Discussion

Papers

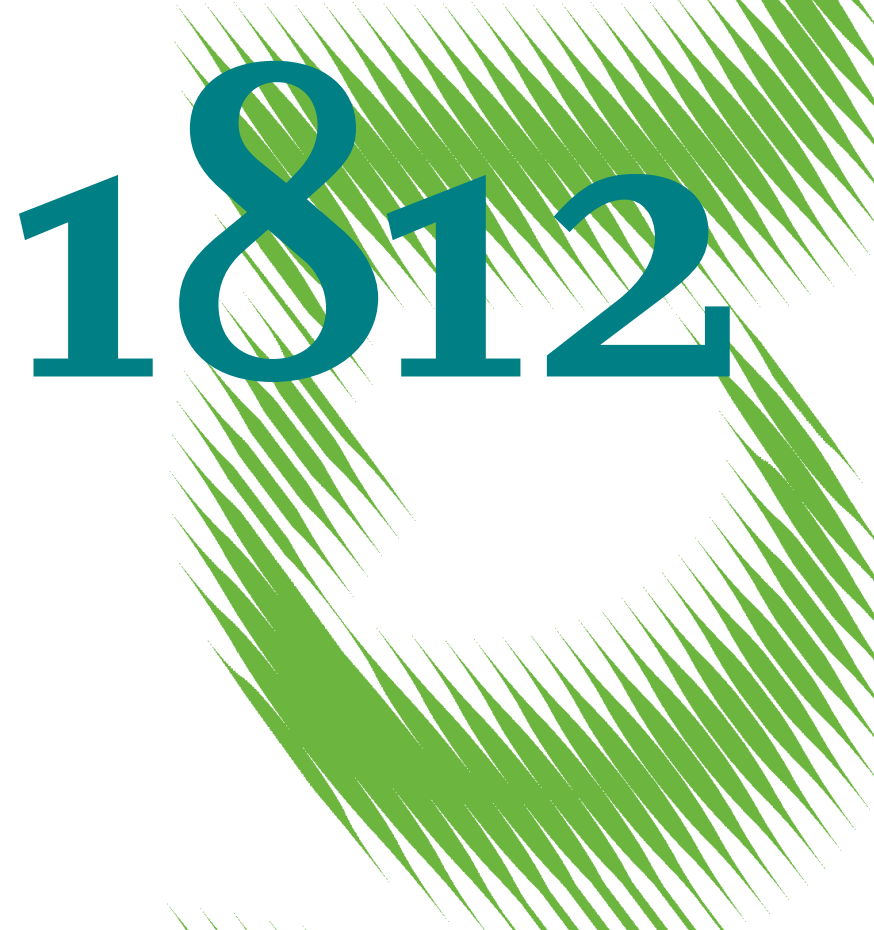

The Impact of Population, Affluence, Technology, and Urbanization on $\mathrm{CO}_{2}$ Emissions across Income Groups 
Opinions expressed in this paper are those of the author(s) and do not necessarily reflect views of the institute.

IMPRESSUM

(C) DIW Berlin, 2019

DIW Berlin

German Institute for Economic Research

Mohrenstr. 58

10117 Berlin

Tel. +49 (30) $89789-0$

Fax +49 (30) $89789-200$

http://www.diw.de

ISSN electronic edition 1619-4535

Papers can be downloaded free of charge from the DIW Berlin website:

http://www.diw.de/discussionpapers

Discussion Papers of DIW Berlin are indexed in RePEc and SSRN:

http://ideas.repec.org/s/diw/diwwpp.html

http://www.ssrn.com/link/DIW-Berlin-German-Inst-Econ-Res.html 


\title{
The Impact of Population, Affluence, Technology, and Urbanization on $\mathrm{CO}_{2}$ Emissions across Income Groups
}

\author{
Lars Sorge ${ }^{\mathrm{a}, \mathrm{b}}$ and Anne Neumann ${ }^{\mathrm{a}, \mathrm{c}}$ \\ ${ }^{\mathrm{a}}$ DIW Berlin, ${ }^{\mathrm{b}}$ Berlin University of Technology, ${ }^{\mathrm{c}}$ NTNU Trondheim
}

\begin{abstract}
July 2019
Abstract: This paper analyzes the impact of urbanization on $\mathrm{CO}_{2}$ emissions within the STIRPAT framework over the period 1971 to 2014 for a panel of 76 countries clustered into income groups. Using dynamic panel estimations techniques, the empirical results robustly show an inverted $\mathrm{N}$-shaped relationship between urbanization and $\mathrm{CO}_{2}$ emissions in the long-term associated with the ecological modernization theory in particular for the lower- and middle-income panel: increasing levels of urbanization tend to reduce $\mathrm{CO}_{2}$ emissions in the long-term. The estimated turning point for the urbanization ratio after which $\mathrm{CO}_{2}$ emissions decline is almost identical and around $54 \%$ both for the lower- and middle-income panel. The long-term relationship for $\mathrm{CO}_{2}$ emissions and its relevant impact factors tends to be similar across groups. The impact of population determines $\mathrm{CO}_{2}$ emissions significantly only in the long-term within any panel. Different from previous studies, the results robustly indicate that GDP per capita does impact $\mathrm{CO}_{2}$ emissions greater than population in any panel. This suggests, that it is rather the growth in consumption than the number of people leading $\mathrm{CO}_{2}$ emissions to increase. Energy efficiency reductions most harmfully effect $\mathrm{CO}_{2}$ emissions within the high-income panel in the long- and short-run.
\end{abstract}

JEL codes: Q5, Q43, R11, C23

Keywords: STIRPAT, carbon dioxide emissions, urbanization, ecological modernization, level of economic development, panel data data methods

This research did not receive any specific grant from funding agencies in the public, commercial, or not-for-profit sectors. Declarations of interest: None. We thank the participants of the $41^{\text {st }}$ IAEE International Conference in Groningen 2018 for fruitful discussion and input. The usual disclaimer applies and all remaining errors are ours. 


\section{Introduction}

While there is general consensus that human activities have accelerated global warming, to what extent demographic dynamics and in particular increasing urbanization levels impact $\mathrm{CO}_{2}$ emissions still is the subject of a controversial debate. With more than six billion people living in urban areas and the worlds population projected to increase to 9.8 billion both by 2050, environmental problems connected to urbanization have become a growing concern over the recent years (United Nations 2014; United Nations 2017). Urban areas for instance are responsible for more than $70 \%$ of global $\mathrm{CO}_{2}$ emissions in 2014 (UN-Habitat, 2016). Moreover, the transition from rural to urban areas is likely to intensify since climate change already leads to inhospitable environments (Stephenson et al., 2010). Understanding the relationship between demographic factors and $\mathrm{CO}_{2}$ emissions in particular for low- and lower-middle-income countries, where both urbanization and population growth are projected to increase the fastest, thus is of great practical importance.

Urbanization does not only imply the demographic transition from rural to urban areas, but similarly is a process of social transformation from an agriculture-based economy to a manufacturing and service oriented economy thus serving as an important indicator for modernization (Sadorsky, 2014). The transition from rural to urban areas intensifies the demand for urban infrastructure and transportation, and stimulates the concentration of consumption and production leading to pollutant emissions. Patterns of urbanization which are linked to and impact structures of modernity however are at least theoretically compatible with ecological sustainability. Following the Ecological Modernization Theory (EMT) processes of further modernization help to resolve the environmental issues caused by modern societies as soon as countries begin to realize the importance of environmental sustainability to their long-term survival (York et al., 2003b; Poumanyvong and Kaneko, 2010). Empirically, however, the relationship between urbanization and the environment still is unclear due to a failure to account for urbanization's varying impact at different stages of economic development and the implicit assumption of a homogeneous impact of 
urbanization for all countries (Poumanyvong and Kaneko, 2010; Liddle, 2013)

In this paper we analyze if the demographic dynamics of modernity such as increasing urbanization levels or population growth are compatible with ecological sustainability in the long-term. Within the context of the Environmental Kuznets Curve (EKC) hypothesis (Grossman and Krueger, 1991) and the Ecological Modernization Theory (EMT) in particular, this paper utilizes the STIRPAT regression framework to empirically test if a threshold level for urbanization exists after which $\mathrm{CO}_{2}$ emissions decrease over the course of further urbanization. This paper contributes to the existing literature on the relationship between $\mathrm{CO}_{2}$ emissions and urbanization by allwoing for non-linear forms of urbanity over time. Moreover, splitting the panel along economic development then helps to identify how the driving forces of $\mathrm{CO}_{2}$ emissions vary across different stages of economic development. Lastly, using dynamic panel estimation techniques which account for the heterogeneity among countries and in which both the short- and long-term impacts are modeled improves the quality of the results.

The remainder of this paper is organized as follows. Section 2 outlines the theoretical underpinnings of the two aforementioned theories concerning modernization and ecological sustainability. Section 3 reviews the literature. Section 4 presents the data and explains the empirical strategy. Section 5 reports the empirical results and Section 6 concludes.

\section{Modernization and Ecological Sustainability}

The evolution of the environmental impacts of modernity which vary over time can be summarized in at least two distinct theories, both of which consider continued modernization necessary to eventually achieve ecological sustainability. First, and following the EKC hypothesis, early stages of economic development are inevitably accompanied by environmental degradation, as environmental awareness is relatively low and environmental friendly technologies simply not available. Output, income, and employment are more important to societies than environmental quality and countries are merely too poor for positive environmental arrangements. As income rises, investments in more 
environmental friendly technologies are realized and the structure of production changes. The transformation towards an information and knowledge based economy together with technological progress, increasing environmental awareness, and environmental regulations becoming more efficient eventually reduces the environmental impact of economic growth. Thus, it is possible to grow out of environmental problems (Dinda, 2004).

Second, and closely related to the EKC hypothesis but originating from the early 1980s, the EMT emphasizes non-economic factors such as social and institutional transformations noticing that economies begin with a different set of institutional and infrastructural patterns with restructuring of institutions that accompanies modernization (Mol and Spaargaren, 2000; York et al., 2003c). It highlights the importance of reflexivity as a key feature of late modernity which eventually results in ecological rationality outweighing economic rationality depending on the development of societies. Industrialization, technological development, economic growth, and capitalism are considered as important drives for environmental reform. Accordingly, environmental problems increase in early stages of development up to a turning point after which further processes of modernization effectively reduce environmentally related issues. It is important to note, that modernization does not automatically lead to sustainability. The institutions of late modernity however do have the potential to ecologically transform production and consumption (York and Rosa, 2003). The process of social transformation partly driven by social movements, nonmovement NGOs and actors within government, business and the scientific establishment, increases the capability of critical and rational self-examination. As modernization further progresses, new forms of rationality evolve and ecological concerns receiving attention equally to economic ones. This process results in ecological valuation being incorporated into economic choices and economic valuation simultaneously applied to ecological thereby incorporating the principles of environmentalism in the design of institutions. The ecological modernization theory further argues that next to modern institutional forms, technological innovations and mindsets diffuse from urban areas with technology being another prime engine of social change. With further modernization, societies can decrease the environmental impact from economic growth through technological innovation, urban 
agglomeration, and realizing the structural change from agriculture-based towards more knowledge and services oriented economies. Eventually, modern, affluent, mostly capitalist societies can achieve sustainability (Mol and Spaargaren, 2000; York et al., 2010). Thus, although the level of economic development is the most important indicator of modernization, urbanization similarly is linked to and impacts structures of modernity (Kasarda and Crenshaw, 1991; Ehrhardt-Martinez, 1998; York et al., 2003c). Thus, following both the EKC and EMT, processes of modernization are at least theoretically compatible with ecological sustainability.

\section{Literature Review}

This section reviews both panel and time-series cross-section studies which analyze the drivers of $\mathrm{CO}_{2}$ emissions using the STIRPAT framework. Liddle and Lung (2010), Liddle (2014), Liddle (2015), Kais and Sami (2016), and Lin et al. (2017) provide an excellent overview of the most recent empirical STIRPAT work. About 30 papers using either panel or time-series cross-section analyze the determinants of anthropogenic country-level $\mathrm{CO}_{2}$ emissions. Eight of them are partially comparable since they use similar income groupings. Although six of them control for urbanization, none allows the urbanization and $\mathrm{CO}_{2}$ emissions relation to be nonlinear. Two time series cross-section data studies utilize a quadratic relation among urbanization and $\mathrm{CO}_{2}$ emissions. However, both do divide the panels into different subgroups.

Fan et al. (2006) analyze the impact of population, GDP per capita, energy intensity, urbanization, and the population aged $15-64$ on $\mathrm{CO}_{2}$ emissions at different levels of economic development. Their five panels comprise 59 low-, 54 lower middle-, 40 upper middle-, 55 high-income economies, a global panel, plus a China only data set over the period 1975 - 2000. They find that the impact of both population and urbanization on $\mathrm{CO}_{2}$ emissions is the highest (lowest) for upper middle- (lower-) income countries. The ratio of the population aged 15 - 64 affects high-income countries (global) $\mathrm{CO}_{2}$ emissions the most (lowest). GDP per capita most strongly increases emissions globally and the lowest 
in upper middle-income economies. The $\mathrm{CO}_{2}$ emissions reduction potential resulting from energy intensity improvements is the greatest in lower middle-income countries but relatively small for the remaining panels including the China only data set.

Poumanyvong and Kaneko (2010) investigate the effects of urbanization on both energy use and $\mathrm{CO}_{2}$ emissions. Their sample contains 99 countries from 1975 to 2005 clustered into all-, high-, middle-, and low-income panels. The model for the estimation of total energy use includes population, GDP per capita, both the share of industry as well as services in GDP, and urbanization as explanatory variables. The model for $\mathrm{CO}_{2}$ emissions additionally contains energy intensity. As Poumanyvong and Kaneko (2010) identify both GDP per capita and energy intensity as nonstationary variables, their empirical results are based on the first-differenced (FD) estimation technique. They find an increasing effect of urbanization on emissions for all income groups but the effect is greater in middle-income economies. The impact of population, GDP per capita, and energy intensity on $\mathrm{CO}_{2}$ emissions is the highest (lowest) in low- (high-) income countries.

Using second generation nonstationary panel time series methods, Liddle (2013) analyzes the impact of urban population and GDP per capita on carbon dioxide emissions from transport over the period 1971 - 2007 for a panel of 85 countries. He separates the economies roughly in line with the World Bank's income level definitions. Liddle (2013) establishes cointegration thus utilizing the Pedroni (2001) Fully Modified OLS (FMOLS) estimation technique to obtain the ecological long-term elasticities. The impact of GDP per capita on carbon dioxide emissions from transport differs only slightly in magnitude between the different panels. The elasticity of carbon dioxide emissions from transport with respect to affluence is significantly smaller in richer countries. The impact of urban population on carbon dioxide emissions from transport is the highest (lowest) in the all countries- (rich-) panel. Based on the elasticity estimates for urbanization at the different stages of economic development, Liddle (2013) finds that urban population's impact follows a U-shaped relationship. He however did not include a squared term of urbanization in his regression specification. 
Li and Lin (2015) investigate the impacts of urbanization and industrialization on both $\mathrm{CO}_{2}$ emissions and total energy consumption for a balanced panel of 73 countries over the period 1971-2010. The countries are clustered into four groupings according to their level of income and they control for population, GDP per capita, energy intensity proxied by energy consumption divided by GDP, industrialization, and urbanization. Their key empirical results concerning $\mathrm{CO}_{2}$ emissions can be summarized as follows: Population increases emissions expect for the high-income panel. The estimated coefficients on GDP per capita are positive in magnitude and the greatest for the middle-/low- and middle/high-income group. Except for the middle-/high-income panel industrialization increases emissions. In the low-, middle-/low-, and high-income panel urbanization increases emissions whereas for the middle-/high-income panel it decreases emissions.

Lin et al. (2017) analyze the impact on both $\mathrm{CO}_{2}$ emissions and greenhouse gas emissions (GHG) over the period 1991 - 2013 for 53 non high-income countries. They use population, GDP per capita, labor productivity, urbanization level, urban employment level, industrialization level, the total population divided by industry value added, $\mathrm{CO}_{2}$ emission intensity, and energy intensity as impact factors. As first generation panel unit root tests confirm stationarity of the variables, they directly estimate the models using fixed and random effects estimation techniques. Lin et al. (2017) conclude that "[t]he main driving factors of $\mathrm{CO}_{2}$ emission remain population, affluence, energy intensity and $\mathrm{CO}_{2}$ emission intensity."

Recently, Shuai et al. (2017) identify the key impact factors on $\mathrm{CO}_{2}$ emission over the period 1990 - 2011 from both time-series and panel data for 125 countries which are clustered into five panels. They use urban population, GDP per capita, and energy intensity as explanatory factors for emissions. Shuai et al. (2017) test for both panel unit roots and panel cointegration and use Ordinary Least Squares (OLS) to estimate the long-term relationship. Their results imply that the impact of urban population on $\mathrm{CO}_{2}$ emissions is the highest (lowest) for the low-income (upper middle-income) panel. Increasing GDP per capita is associated with the highest (lowest) increase in $\mathrm{CO}_{2}$ emissions for the lower middle- (high-) income panel. Energy intensity appears to be a key impact 
factor across different stages of economic development except for the low-income panel.

Martínez-Zarzoso and Maruotti (2011) analyze the impact of urbanization on $\mathrm{CO}_{2}$ emission for a panel of 88 developing countries from 1975 - 2003. The countries are clustered into income groupings and the resulting panels are unbalanced. Martínez-Zarzoso and Maruotti (2011) use the following variables in different STIRPAT specifications: population, GDP per capita, energy efficiency, the percentage of total population living in urban areas, the percentage of population between 15 and 64 years old, the percentage of population older than 64 , and the percentage of the industrial activity with respect to the total production measured by the GDP. They find an inverted U-shaped pattern for the relationship between urbanization and $\mathrm{CO}_{2}$ emissions with an estimated turning point of $36 \%$ for the upper middle-income panel and $41 \%$ for the lower middle-income panel. For the full sample of developing countries, their results indicate an inverted U-shaped relationship between urbanization and $\mathrm{CO}_{2}$ emissions in accordance with the ecological modernization theory.

Zhang and Chen (2017) allow for nonlinearities to analyze the impact of population, GDP per capita, population ages 65 and above, annual real growth rate of GDP, trade openness, and urbanization on $\mathrm{CO}_{2}$ emission using data on 141 countries over the period 1961 - 2011. They construct a global panel as well as an OECD, Non-OECD, and an Asia only panel. Their empirical results from a two-way fixed effects model suggest an inverted U-shaped relationship between urbanization and $\mathrm{CO}_{2}$ emission only in the OECD panel: accordingly, $\mathrm{CO}_{2}$ emission start to decline after urbanization levels reach $74 \%$. Urban primacy and the percentage of the population in the largest city in the urban population have significant impacts on $\mathrm{CO}_{2}$ emissions, too. All studies suffer from econometric and methodological deficiencies thus leaving room for improvement: First, except for Liddle (2013) and Li and Lin (2015), none of the above accounts for cross-sectional dependence. Poumanyvong and Kaneko (2010) find all variables stationary except for GDP per capita and energy intensity. Since they do not test for cointegration, Poumanyvong and Kaneko (2010) focus on the empirical results obtained with all variables in their first differences. Li and Lin (2015) similarly do not test for cointegration but their panel unit root test 
results suggest nonstationarity for the series on industrialization and population. Given Li and Lin (2015) use the first difference of the the variables in one estimation, the ecological elasticities are only interpretable as short-run as opposed to long-term elasticites. Both, Martínez-Zarzoso and Maruotti (2011) and Lin et al. (2017) use first generation panel unit root tests which do not account for cross-section-dependence and find all variables stationary in levels. Lin et al. (2017) moreover conduct the panel unit root test for the overall panel only. Similarly, Shuai et al. (2017) find evidence for panel unit roots and cointegration in every income panel using first generation methods. Liddle (2013) on the contrary uses both first and second generation panel unit root and cointegration tests. Lastly, Zhang and Chen (2017) do not check the stationarity properties of the variables. The issue of parameter heterogeneity is only addressed by Liddle (2013) using the FMOLS estimation technique by allowing the slope coefficients to vary across panel members. To summarize, all studies suffer from either econometric or methodological deficiencies. From a methodological perspective, Liddle (2013) does not include nonlinear forms of urbanization into the regression specification. Both studies which allow for nonlinearities however apply if at all first-generation panel unit root tests but do not address the issue of parameter heterogeneity. Moreover, none of the studies allows the relationship between urbanization and $\mathrm{CO}_{2}$ emissions to follow other patterns than U-shaped or inverted U-shaped.

\section{Data and Methodology}

Section 4.1 presents a descriptive analysis of the utilized panel dataset. Section 4.2 outlines the empirical specification for the cubic STIRPAT model. Section 4.3 presents the empirical strategy applied to obtain the ecological elasticities and to identify if a threshold level for urbanization exists after which $\mathrm{CO}_{2}$ emissions decrease over the course of further urbanization. 


\subsection{Data}

The panel dataset contains data from the World Development Indicators (WDI) from The World Bank for 76 economies covering the period 1971 to 2014 in annual frequency. ${ }^{1}$ The analysis is conducted at an aggregate level and includes as many countries as possible clustered into three panels based on their level of high-, middle- and lowerincomes as well as an all-income panel for the longest period available. ${ }^{2}$ With $\mathrm{T}=44$ in each income panel for every given variable, the high-income panel $(\mathrm{N}=31)$ has 1,364 observations, the middle-income panel $(\mathrm{N}=20)$ has 880 observations, and the lower-income panel $(\mathrm{N}=25)$ has 1,110 observations.

Figure 1: Regional coverage by income group

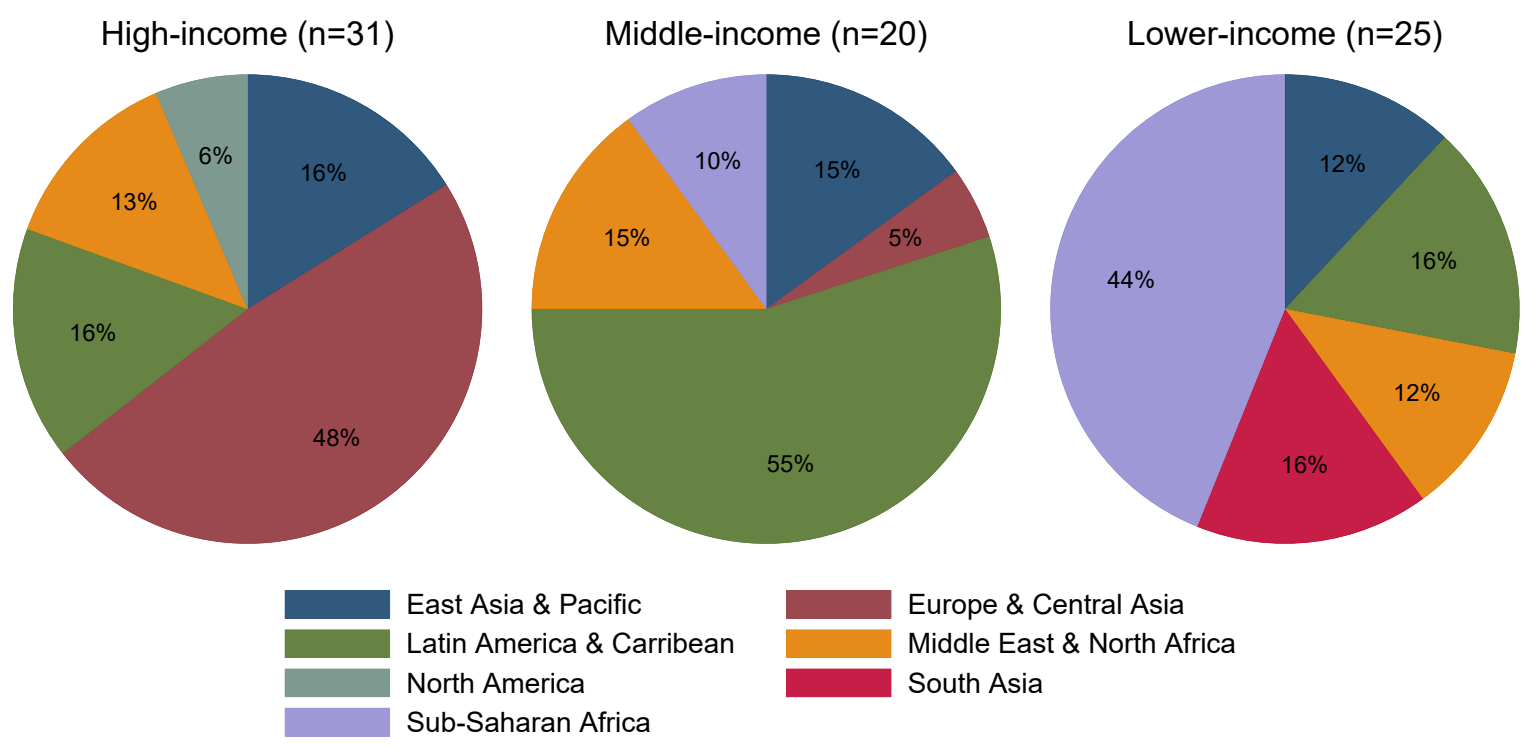

Notes: Own depiction.

The all-income panel $(\mathrm{N}=76)$ contains countries from the seven regions as defined by the World Bank: 20 countries from Latin America and Caribbean (26\%), 16 countries from Europe and Central Asia (21\%), 13 countries from Sub-Saharan Africa (17\%), 11 countries from East Asia and Pacific (14\%), 10 countries from Middle East and North Africa (13\%), four countries from South Asia (5\%), and two countries from North America

\footnotetext{
${ }^{1}$ At the time of writing no more consistent recent data on the energy intensity variable was available.

${ }^{2}$ The low-income countries are included in the lower-income panel due to the lack of data availability for these countries. Singapore is excluded from the analysis as the urbanization ratio is at $100 \%$ in every single year over the period 1971 to 2014 and thus contains no variation at all.
} 
(3\%). Figure 1 shows the regional coverage across the strongly balanced income panels.

The dependent variable for environmental impact is $\mathrm{CO}_{2}$ emissions measured in metric tons, population is total population in midyear estimates, and affluence is per capita real GDP measured in constant 2010 USD. The impact of technology is approximated using a measure of energy intensity calculated as total energy use ( $\mathrm{kg}$ of oil equivalent) divided by GDP (measured in constant 2010 USD) necessary to support economic activity. Decreasing energy intensity then reflects a higher degree of overall efficiency of economic activities in terms of energy consumption which ultimately leads to $\mathrm{CO}_{2}$ emissions reductions (Fan et al., 2006). Urbanization is measured as the share of the population living in urban areas. ${ }^{3}$

Table 1: Summary statistics by panel $(1971-2014)$

\begin{tabular}{|c|c|c|c|c|c|c|c|c|c|c|}
\hline & \multicolumn{2}{|c|}{$\mathrm{CO}_{2}$} & \multicolumn{2}{|c|}{$\mathrm{P}$} & \multicolumn{2}{|c|}{ GDP } & \multicolumn{2}{|c|}{ EI } & \multicolumn{2}{|c|}{$\mathrm{U}$} \\
\hline & Mean & $\mathrm{SD}$ & Mean & $\mathrm{SD}$ & Mean & $\mathrm{SD}$ & Mean & SD & Mean & $\mathrm{SD}$ \\
\hline Global & 227.28 & 792.56 & 57.6 & 171.0 & $13,239.50$ & $17,008.88$ & 0.27 & 0.23 & 58.37 & 21.71 \\
\hline High-income & 324.67 & 895.35 & 27.0 & 50.1 & $28,179.48$ & $17,960.64$ & 0.15 & 0.11 & 76.33 & 13.09 \\
\hline Middle-income & 285.49 & $1,020.07$ & 88.6 & 248.0 & $4,943.71$ & $2,678.49$ & 0.27 & 0.24 & 57.10 & 14.88 \\
\hline Lower-income & 59.96 & 204.35 & 69.9 & 185.0 & $1,350.56$ & 772.01 & 0.42 & 0.25 & 37.12 & 13.81 \\
\hline
\end{tabular}

Notes: $\mathrm{CO}_{2}$ emissions are in metric kilo tons; Population is in million; GDP per capita is in constant 2010 USD; energy intensity is in kg of oil equivalent energy use per constant 2010 USD; urbanization is in percent. Mean is the arithmetic mean; standard deviation is denoted by SD; data obtained from the World Development Indicators (WDI) database from The World Bank (last updated 14 November 2018).

Average $\mathrm{CO}_{2}$ emissions for the high-income panel are 5.41 (1.14) times higher compared to the lower- (middle-) income panel, whereas average $\mathrm{CO}_{2}$ emissions for the middleincome panel are 4.76 times higher compared to the lower-income panel. The average size of the population is the highest for the middle-income panel: it is 3.21 (1.27) times higher than the average size of the population in the high- (lower-) income panel. In the lower-income panel, the average size of population is 2.53 times higher than in the high-income panel. The high-income panel is 20.87 (5.70) times wealthier than the lower(middle-) income panel in terms of average GDP per capita, whereas average GDP per capita in the middle-income panel is 3.66 times higher compared to the lower-income panel. The lower-income panel is the least energy efficient indicated by the highest value

\footnotetext{
${ }^{3}$ According to The World Bank, urban areas are defined by national statistical offices. Thus, countries may differently classify population as urban or rural. The indicator is calculated using World Bank population estimates and urban ratios from the United Nations World Urbanization Prospects.
} 
Figure 2: Boxplots by panels
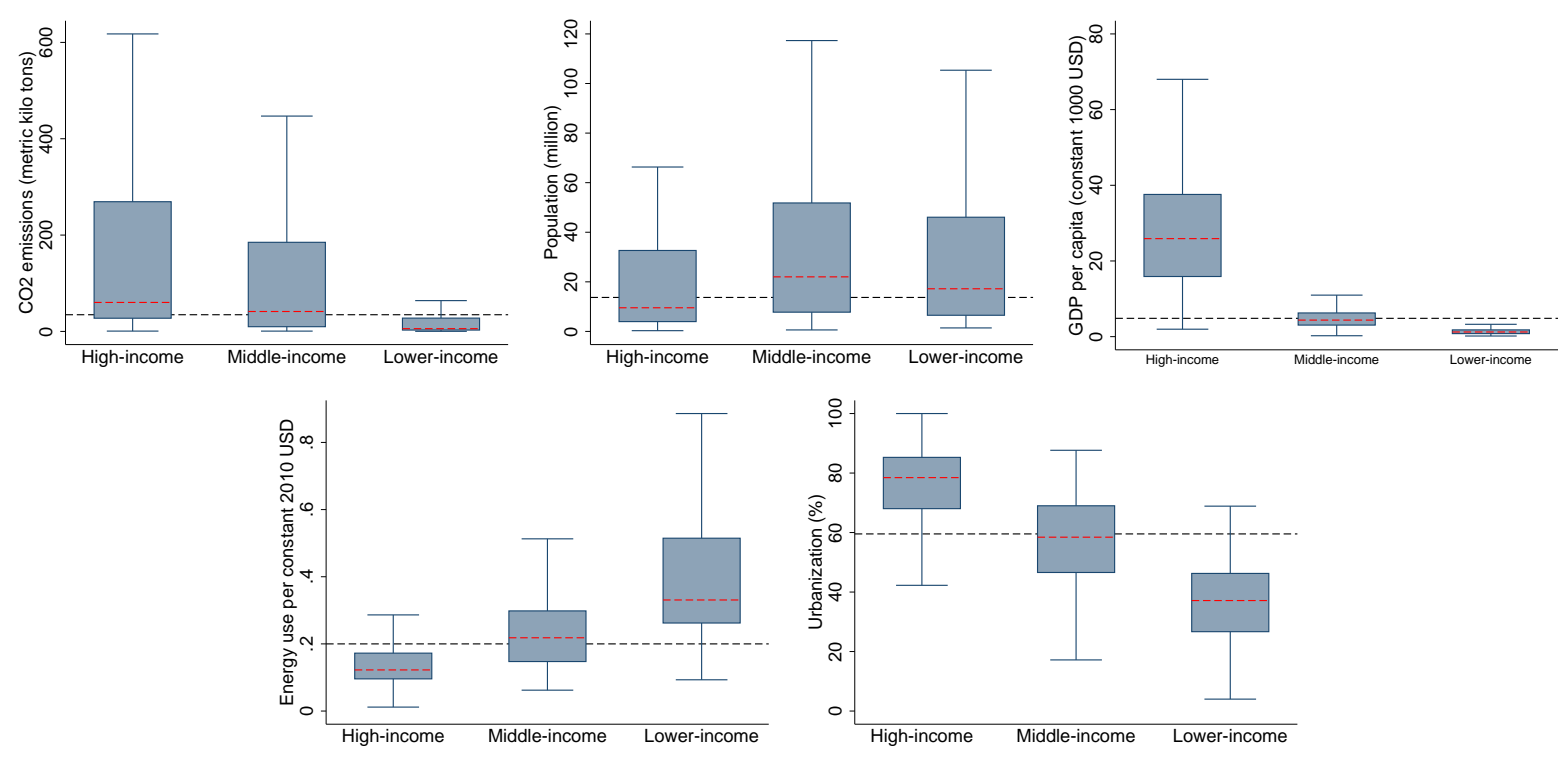

Notes: The red (black) dashed lines indicate the median for each income group (the panel). $\mathrm{CO}_{2}$ emissions are in metric kilo tons; Population is in million; GDP per capita is in constant 2010 USD; energy intensity is in $\mathrm{kg}$ of oil equivalent energy use per constant 2010 USD; urbanization is in percent. Data obtained from the World Development Indicators (WDI) database from The World Bank (last updated 14 November 2018).

for the mean on energy intensity: average energy intensity is 2.71 (1.55) times higher in the lower-income panel than in the high- (middle-) income panel. In the middle-income panel, average energy intensity is 1.75 times higher compared to the the high-income panel. The average ratio of people living in urban areas for the high-income panel is 2.06 (1.34) times higher than the ratio of people living in urban areas for the lower- (middle-) income panel. The average urbanization ratio in the middle-income panel is 1.54 times higher than in the lower-income panel.

\subsection{Empirical Specification}

Ehrlich and Holdren (1972) summarized the major driving forces of human activites (I) on the environment as a product of population $(\mathrm{P})$, affluence $(\mathrm{A})$, and technology $(\mathrm{T})$. Accordingly, population and income growth as well as technological progress significantly impact the human-environment relationship simultaneously:

$$
I=P A T
$$


During the 1990s, the IPAT identity was redefined (Kaya, 1990) as an equation that relates to the driving forces of anthropogenic carbon dioxide emissions. Both concepts (IPAT and Kaya-identity) are used by the Intergovernmental Panel on Climate Change (IPCC) as an accounting identity to analyze energy-related carbon dioxide emissions. Dietz and Rosa (1994) translate the IPAT identity into the Stochastic Impacts by Regression on Population, Affluence and Technology (STIRPAT) model represented by:

$$
I=a P^{b} A^{c} T^{d} e
$$

Taking the logarithm results in an additive linear regression model that is no longer an accounting identity anymore, which facilitates hypothesis testing:

$$
(\ln I)=a+b(\ln P)+c(\ln A)+d(\ln t)+e,
$$

where $e$ is an error term and the estimated coefficients then represent the ecological elasticity of each impact factor (York et al., 2003a).

Drawing on the ecological modernization theory and using the STIRPAT regression framework, we specify the following model to identify if a threshold level for urbanization exists after which $\mathrm{CO}_{2}$ emissions decrease over the course of further urbanization:

$$
C O_{2 i t}=\beta_{0 i}+\beta_{1 i} P_{i t}+\beta_{2 i} G D P_{i t}+\beta_{3 i} E I_{i t}+\beta_{4 i} U_{i t}+\beta_{5 i} U_{i t}^{2}+\beta_{6 i} U_{i t}^{3}+\epsilon_{i t},
$$

where $i=1, \ldots, N$ and $t=1, \ldots, T$ refer to country and time indexes, respectively. The parameter $\beta_{0 i}$ are country-specific intercepts, $\mathrm{CO}_{2}$ is carbon dioxide emissions, $P$ is population $G D P$ is GDP per capita, $E I$ is energy intensity, and $\epsilon_{i t}$ represents the idiosyncratic error term. All variables are converted into natural logarithms. The sign of the coefficient on both $\beta_{1}$ and $\beta_{2}$ is expected to be positive for all panels as increasing population as well as GDP per capita yields an increase in $\mathrm{CO}_{2}$ emissions. Since energy intensity reflects trends in overall energy use relative to economic output, the estimated coefficient is a proxy for efficiency improvements. Thus, the effect of energy intensity on 
$\mathrm{CO}_{2}$ emissions $\left(\beta_{3}\right)$ is expected to be most substantial for the high-income panel and the lowest lower-income panel. Moreover, following both EKC and EMT, higher stages of modernity are associated with a lower environmental impact of economic growth. ${ }^{4}$ Depending on the signs and significance of the coefficients for $\beta_{4}, \beta_{5}$, and $\beta_{6}$ seven functional patterns between $\mathrm{CO}_{2}$ emissions and urbanization can emerge. ${ }^{5}$

\subsection{Empirical Strategy}

Before estimating the ecological elasticities and potentially identifying if a threshold level for urbanization exists after which $\mathrm{CO}_{2}$ emissions decrease over the course of further urbanization, all variables are tested for any degree of cross-section dependency using the cross-section dependence (CD) test suggested by Pesaran (2004) which is applicable to stationary and unit root dynamic heterogeneous panels. The cross-section independency assumption from first generation panel unit root tests is considered to be too restrictive (Banerjee et al., 2004)) and we thus employ the Pesaran (2007) panel unit root test. It based on adjusting the ADF regressions with the cross-section average of lagged levels and first differences of the individual series. The homogeneous null hypothesis is that each country in the panel contains a unit root and is tested against the heterogeneous alternative that allows to differ across countries. The presence of a unit root indicates that shocks will have permanent effects whereas for a stationary process, a shock will result in only a temporary deviation from the variable's long-term growth path (Smyth, 2013).

We use the dynamic heterogeneous panel autoregressive distributed-lag (ARDL) approach to obtain the ecological elasticities and to determine if a threshold level for urbanization exists (Pesaran and Smith, 1995, Pesaran 1997, and Pesaran et al. 2001).

\footnotetext{
${ }^{4}$ Different technology parameters such as $\mathrm{CO}_{2}$ emissions per unit of output $\left(\mathrm{CO}_{2} / \mathrm{GDP}\right)$ or $\mathrm{CO}_{2}$ emissions per unit of total energy use $\left(\mathrm{CO}_{2} / \mathrm{E}\right)$ cannot be included in the model as both technology proxies contain parts of the dependent variable (Poumanyvong and Kaneko (2010).

${ }^{5}$ i) $\beta_{4}=\beta_{5}=\beta_{6}=0$ results in a flat pattern, ii) $\beta_{4}>0$ and $\beta_{5}=\beta_{6}=0$ shows a monotonic increasing or linear relationship, iii) $\beta_{4}<0$ and $\beta_{5}=\beta_{6}=0$ reveals a monotonic decreasing relationship, iv) $\beta_{4}>0, \beta_{5}<0$ and $\beta_{6}=0$ produces an inverted U-shaped figure, v) $\beta_{4}<0, \beta_{5}>0$ and $\beta_{6}=0$ yields and U-shaped form, vi) $\beta_{4}>0, \beta_{5}<0$ and $\beta_{6}>0$ produces a cubic polynomial or a N-shaped curve, and lastly vii) $\beta_{4}<0, \beta_{5}>0$ and $\beta_{6}<0$ represents an inverted N-shaped figure (Dinda, 2004). The peak and trough points for the cubic models are calculated by taking the antilog of $\frac{-\beta_{5} \pm\left(\beta_{5}^{2}-3 \beta_{4} \beta_{5}\right)^{1 / 2}}{3 \beta_{6}}$.
} 
The ARDL $(\mathrm{p}, \mathrm{q})$ model, with $\mathrm{p}$ the lag lengths of the dependent variable and $\mathrm{q}$ the lag lengths of the explanatory variables, is categorized as an error correction model. Using the $\operatorname{ARDL}(\mathrm{p}, \mathrm{q})$ approach allows to identify both short- and long-term dynamics of various impact factors for anthropogenic $\mathrm{CO}_{2}$ emissions.

Due to its high degree of flexibility, the ARDL $(p, q)$ approach is very appealing: variables which have a different order of integration can be used irrespective of whether the variables of interest are $\mathrm{I}(0)$ or $\mathrm{I}(1)$. Moreover, the inclusion of lags of both the dependent and independent variables eliminates problems resulting from endogeneity.

The extended dynamic heterogeneous ARDL ( $\left.\mathrm{p}, \mathrm{q}_{1}, \ldots, \mathrm{q}_{6}\right)$ specification of the hypothesized pollution environment relationship given in (5) then takes the following form:

$$
\begin{gathered}
C O_{2 i t}=\beta_{0 i}+\sum_{j=1}^{p} \lambda_{i j} C O_{2 i, t-j}+\sum_{j=0}^{q_{1}} \delta_{1 i j} P_{i, t-j}+\sum_{j=0}^{q_{2}} \delta_{2 i j} G D P_{i, t-j}+\sum_{j=0}^{q_{3}} \delta_{3 i j} E I_{i, t-j}+ \\
\sum_{j=0}^{q_{4}} \delta_{4 i j} U_{i, t-j}+\sum_{j=0}^{q_{5}} \delta_{5 i j} U_{i, t-j}^{2}+\sum_{j=0}^{q_{6}} \delta_{6 i j} U_{i, t-j}^{3}+\epsilon_{i t} .
\end{gathered}
$$

Assuming the variables of interest are $\mathrm{I}(1)$ and cointegrated, the error term $\epsilon_{i t}$ then becomes a stationary $\mathrm{I}(0)$ process for all $i$ and equation (5) can be rewritten as an errorcorrection model. An underlying feature of cointegrated variables in an error-correction model is their responsiveness to any long-term changes: when unexpected shocks occur, the system converges back to the long-term cointegrating relationship while allowing for short-run adjustment dynamics. Thus, reparameterization of (5) yields the following error-correction model:

$$
\Delta C O_{2 i t}=\beta_{0 i}+\phi_{i}\left(C O_{2 i, t-1}-\theta_{i} X_{i t}\right)+\sum_{j=1}^{p-1} \lambda_{i j}^{*} \Delta C O_{2 i, t-j}+\sum_{j=0}^{q-1} \delta_{i j}^{*} \Delta X_{i, t-j}+\epsilon_{i t}
$$

where $X_{i t}=P_{i t}, G D P_{i t}, E I_{i t}, U_{i t}, U_{i t}^{2}, U_{i t}^{3}$ is the vector of explanatory variables containing information on regressors which vary across countries and time periods. The expression $\Delta$ denotes the first difference operator and the number of lags $j$ is determined by using standard model selection criteria. The term in brackets contains the long-term relationship between the explanatory variables. The parameter $\phi_{i}$ is the error correction or speed of 
adjustment term and determines the time it takes for the system to converge back to the long-term equilibrium. A negative coefficient on the error-correction term provides evidence for a long-term relationship. Stability of the model requires the error-correction term to be not lower than -2 which is within the unit circle (Loayza et al., 2006).

We use two alternative commonly used techniques proposed by Pesaran and Smith (1995) and Pesaran et al. (1999) to estimate the short- and long-term dynamics. The Mean Group (MG) estimation technique allows all coefficients to be heterogeneous: the country specific intercepts, and both the short- and long-term dynamics as well as the error variances are permitted to differ across countries. Thus, the MG estimator does not impose any homogeneity restrictions on the parameters for the cross-section members. For each cross-sectional member, separate regressions are estimated and the coefficients are calculated as unweighted averages of the estimated coefficients (Pesaran and Smith, 1995). Traditional pooled methods, such as the fixed and random effects estimators, only allow for individual specific intercepts. All other coefficients including the error variances are restricted to be the same across countries.

Using the Pooled Mean Group (PMG) estimator offers an intermediate estimation technique involving both pooling and averaging: The PMG estimator allows both the individual specific intercepts and short-run dynamics as well as the error variances to differ across countries. The long-term parameters however are constrained to be homogeneous, that is constant across the groups. Compared to fixed and random effects estimation procedures, both the MG and PMG estimator have the advantage that the dynamic specifications are allowed to vary across panel members. Both estimators require the relative size of the time as well as country dimension to be sufficiently large. The MG estimator always provides consistent estimations of the long-term parameters, but produces inefficient estimates compared to the PMG estimation technique if the long-term slope homogeneity assumption is true. A Hausman (1987) specification test identifies whether the difference between the two estimators is significant in order to choose the appropriate estimation technique in terms of efficiency and consistency. If the null hypothesis of the Hausman test (the difference in the coefficients is not systematic, that is the estimator 
is indeed an efficient and consistent estimator) is not rejected, the PMG method is the estimation technique to be chosen as it then is more efficient (Pesaran et al., 1999).

\section{$5 \quad$ Empirical Results}

First, we identify the degree of multicollinearity among the variables included. While time-series studies are plagued with multicollinearity, panel time series data offers a big advantage: due to an increased sample size the increasing degrees of freedom drastically reduce the problem of multicollinearity (Hsiao, 2014). The result of the multicollinearity test (Table 2 in the appendix) indicates, that values of the variance inflation factor (VIF) for the explanatory variables are all below 10 in any income group, which is a commonly used rule of thumb (Montgomery et al., 2001). Thus, the panel based regression results will not be affected by multicollinearity. The results of the Pesaran (2004) CD (Table 3 in the appendix) indicate that except for the energy intensity indicator in the middleincome panel, all variables are highly dependent across countries in any panel. Given this cross-sectional dependence we use a second-generation panel unit root test which accounts for cross-section dependence. The outcome of Pesaran (2007) panel unit root tests, which include both an intercept only and an intercept and linear trend specification, does not vary greatly between income groups. The results (Table 4 in the appendix) support evidence of a unit root for the series on $\mathrm{CO}_{2}$ emissions, population, GDP per capita, and energy intensity particularly in both the all- and high-income panel. The series on urbanization tends to be stationary in levels across all panels. The results for the series in first differences indicate that $\mathrm{CO}_{2}$ emissions, population, GDP per capita, and energy intensity are significantly integrated of order one within any panel.

\subsection{Pooled Mean Group Estimation Results}

We now turn to the discussion of the MG and PMG estimates to obtain the ecological elasticity of each impact factor and to test the validity of the ecological modernization hypothesis. The lag length of the independent variables is set to one and a common 
lag structure in every panel to make short-run parameters of the resulting first-order autoregressive distributed-lag model comparable across panels is imposed (Loayza and Rancierce, 2006). Figure 3 shows the ecological elasticites for each impact factor by income group. A Hausman (1987) specification test identifies which estimator satisfies the long-term homogeneity assumptions of the respective estimation technique. ${ }^{6}$

The null hypothesis of the Hausman (1987) test is not rejected for any panel and therefore we choose the PMG estimator. The long-term parameters are constrained to be homogeneous; that is constant across groups. Although all panels differ greatly in terms of $\mathrm{CO}_{2}$ emissions, population, GDP per capita, energy intensity, and urbanization, the long-term relationship for $\mathrm{CO}_{2}$ emissions and its relevant demographic and economic factors tends to be similar across all groups. The coefficients on the error-correction term are highly statistically significant at the $1 \%$ level and have a negative sign thus strongly suggesting evidence for cointegration in any panel. The long-term coefficients on population, GDP per capita, and energy intensity are significant at the $1 \%$ significance level whereas the significance for the coefficients on urbanization in particular varies across the level of economic development. The short-run coefficients on both GDP per capita and energy intenstiy are statistically significant at any conventional significance level whereas the short-run coefficients on both population and urbanization are insignificant in any panel.

On a global scale, a $1 \%$ increase in population is associated with an increase in $\mathrm{CO}_{2}$ by $0.855 \%$. The long-term results show that the impact of population on $\mathrm{CO}_{2}$ emissions tends to be the highest (lowest) for the middle- (high-) income panel. The reaction in $\mathrm{CO}_{2}$ emissions due to a change in population is inelastic in any panel except for the middle-income panel. The insignificant short-run impact of population in any panel indicates that population effects manifest in the long-term only. Carbon dioxide emissions with respect to GDP per capita are elastic in any panel in the long-term. Moreover, GDP per capita does impact $\mathrm{CO}_{2}$ emissions higher than does population in any group. The

\footnotetext{
${ }^{6}$ The Hausman (1987) test results as well as both the detailed MG and PMG estimation outcomes are in Table 6 in the appendix.
} 
Figure 3: Estimated long-term coefficients by panel

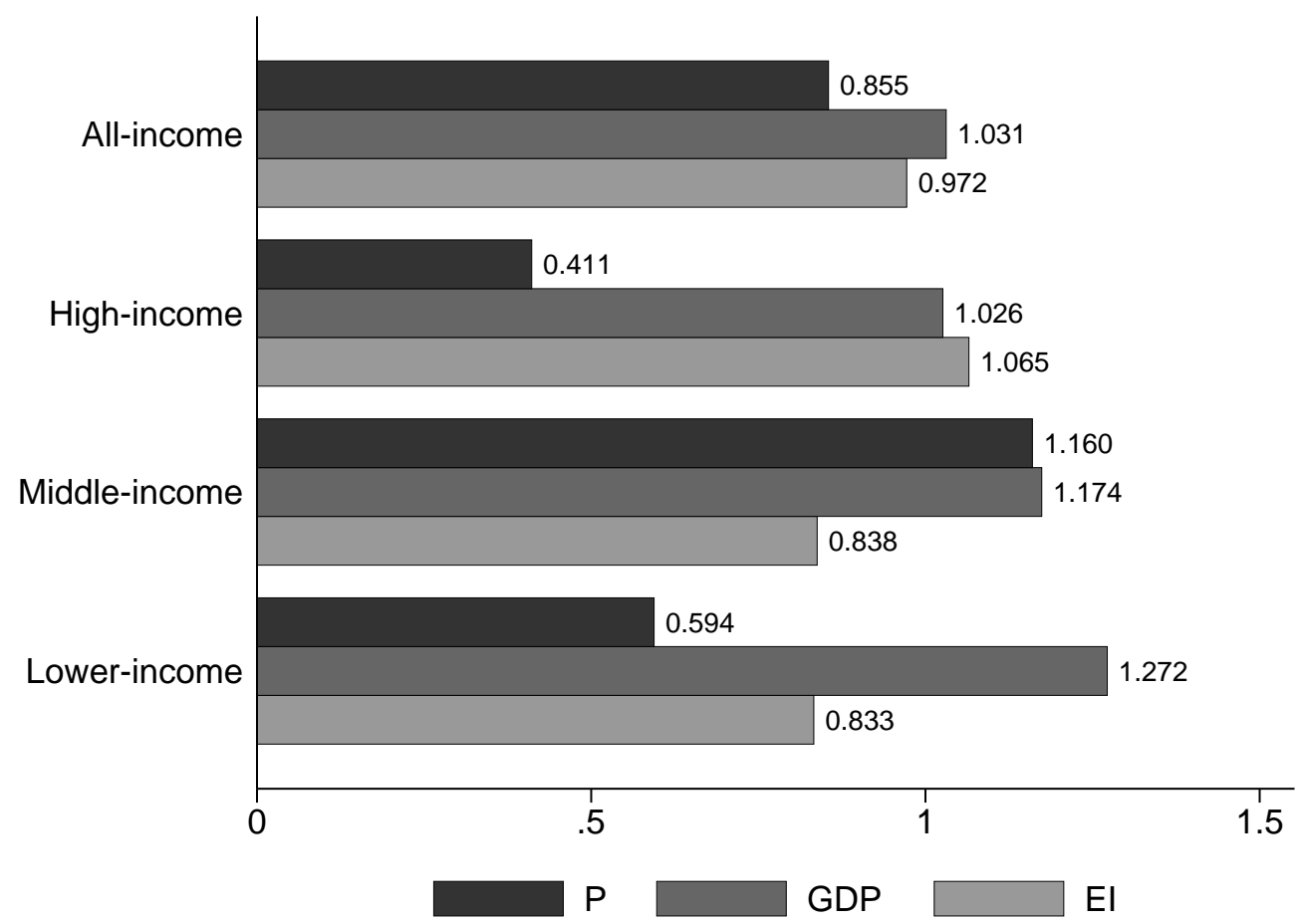

Notes: P is population, GDP is GDP per capita, and EI is energy intensity.

long-term results show that the influence of GDP per capita on $\mathrm{CO}_{2}$ emissions is the highest (lowest) for the lower- (high-) income panel: a 1\% increase in GDP per capita is associated with an increase in $\mathrm{CO}_{2}$ emissions by $1.272 \%$ (1.026 \%). Output growth significantly increases $\mathrm{CO}_{2}$ emissions the most in the lower-income panel in the short-run, too.

The long-term impact of energy intensity on $\mathrm{CO}_{2}$ emissions is inelastic in any panel except for the high-income panel and thus the highest (lowest) for high- (lower-) income panel. Globally, a 1\% increase in energy intensity (which indicates energy efficiency losses) is associated with an increase in $\mathrm{CO}_{2}$ emissions by $0.972 \%$. The short-run impacts of energy intensity on $\mathrm{CO}_{2}$ emissions are the highest (lowest) in the high- (middle-) income panel. Overall, the results indicate, that energy efficiency reductions on average most harmfully effect countries within the high-income panel in both the long- and short-run.

All three coefficients on urbanization are statistically significant on every conventional significance level except for the high-income panel. The long-term coefficients on $\beta_{4}, \beta_{5}$, 
and $\beta_{6}$ are statistically significant and $\beta_{4}<0, \beta_{5}>0$ and $\beta_{6}<0$, which suggests an inverted N-shaped relationship between $\mathrm{CO}_{2}$ emissions and urbanization with the troughs to occur before the peaks. For the global panel, the curve for $\mathrm{CO}_{2}$ emissions reaches the trough at an urbanization level of $13 \%$, then increases up to the peak at $65 \%$ urbanization, and declines again afterwards. For the middle- (lower-) income panel, the curve for $\mathrm{CO}_{2}$ emissions reaches the trough at an urbanization level of $39 \%(8 \%)$, then increases up to the peak at $54.2 \%$ (53.9\%) urbanization, and declines afterwards again. This suggest, that once urbanization reaches a certain threshold, the effect of urbanization on $\mathrm{CO}_{2}$ emissions appears to be negative and thus eventually decrease $\mathrm{CO}_{2}$ emissions in the long-term.

\subsection{Robustness}

Following the logic of the EKC hypothesis, the assumption of a linear relationship between affluence and $\mathrm{CO}_{2}$ emissions might be misleading. Therefore, we additionally incorporate quadratic and cubic terms for affluence to consider both EKC and EMT within the STIRPAT regression framework in order to check the robustness of the results. Essentially we test if a threshold level for GDP per capita as well as urbanization exists after which $\mathrm{CO}_{2}$ emissions decrease over the course of economic development using the following model:

$$
\begin{gathered}
C O_{2 i t}=\psi_{0 i}+\psi_{1 i} P_{i t}+\psi_{2 i} G D P_{i t}+\psi_{3 i} G D P_{i t}^{2}+\psi_{4 i} G D P_{i t}^{3}+ \\
\psi_{5 i} E I_{i t}+\psi_{6 i} U_{i t}+\psi_{7 i} U_{i t}^{2}+\psi_{8 i} U_{i t}^{3}+\epsilon_{i t} .
\end{gathered}
$$

Detailled results for the MG and PMG estimations and the Hausman (1987) test are shown in Table 7 in the appendix. The PMG estimator again is more efficient than the MG estimator in any panel. The long-term parameters are constrained to be homogeneous; that is constant across groups which again indicates that the long-term impact of the relevant demographic and economic factors for $\mathrm{CO}_{2}$ emissions tends to be similar across all groups. The coefficients on the error-correction term are highly statistically significant at the $1 \%$ level and have a negative sign thus signaling cointegration in any panel. The 
long-term coefficients on population, energy intensity, and all three urbanization terms are statistically significant at any conventional significance, whereas the significance for the coefficients on GDP per capita varies across panels. Now, only the short-run coefficients on energy intensity are statistically significant at any conventional significance level in any panel.

The reaction in $\mathrm{CO}_{2}$ emissions due to a change in population is still inelastic in any panel except for the middle-income panel. The long-term results show that the impact of population on $\mathrm{CO}_{2}$ emissions again tends to be highest in the middle-income panel but now the lowest for the lower-income group. A $1 \%$ increase in population is associated with an increase in $\mathrm{CO}_{2}$ by $0.664 \%$ on a global scale. The short-run coefficients on population remain insignificant in any panel.

The three coefficients on GDP per capita are statistically significant on every conventional significance level only for the high- and middle income group. For the high-income panel, the long-term coefficients suggest an inverted N-shaped relationship between $\mathrm{CO}_{2}$ emissions and GDP per capita with the trough to occur before the peaks. The curve for $\mathrm{CO}_{2}$ emissions reaches the trough at 291.809 USD per capita GDP then increases up to the peak at 97,275 USD per capita GDP, and declines afterwards again. Both turning points fall into the range of per capita GDP for the high-income panel. For the middle-income panel, the long-term coefficients now suggest a N-shaped relationship between $\mathrm{CO}_{2}$ emissions and GDP per capita with the peak to occur before the trough. Thus, $\mathrm{CO}_{2}$ emissions increase with GDP per capita up to a turning point and then decrease with higher per capita income but eventually increase again after the through is reached. The roots of the first derivative within the middle-income panel however are in the complex plane. A first turning point or peak income does not exist for the estimated emission curve: the trough occurs at 7,428 USD per capita which is in the range of per capita GDP for the middle-income panel. Although the coefficients are statistically significant and show both the signs and magnitudes corresponding to a N-shaped EKC, the relationship between $\mathrm{CO}_{2}$ emissions and income is rather monotonically increasing for the middle-income panel. 
The coefficients on energy intensity do not change substantially. The long-term impact on $\mathrm{CO}_{2}$ emissions is now inelastic in any panel, the highest for the high-income panel and the lowest for the middle-income panel. Again, the short-run impacts of energy intensity on $\mathrm{CO}_{2}$ emissions are the highest (lowest) in the high- (middle-) income panel. The results still indicate that energy efficiency reductions on average most harmfully effect countries within the high-income panel in both the long- and short-run.

All three coefficients on urbanization are statistically significant on every conventional significance level now in any panel. For the all-income panel, the estimated long-term coefficients now suggest a N-shaped relationship instead of an inverted N-shaped figure between $\mathrm{CO}_{2}$ emissions and urbanization. The peak thus now occurs before the trough. As the roots of the first derivative within the all-income panel are in the complex plane, a first turning point or peak urbanization ratio level does not exist for the estimated emission curve: the trough occurs at an urbanization level of $45 \%$. Thus, the relationship between $\mathrm{CO}_{2}$ emissions and urbanization changed and now is rather monotonically increasing for the all-income panel. For the high-income panel, the outcome also changes when affluence in squared and cubic terms is additionally included. The estimated long-term coefficients now suggests an inverted $\mathrm{N}$-shaped instead of a N-shaped relationship between $\mathrm{CO}_{2}$ emissions and urbanization. The trough now occurs before the peak for the high-income group. For both the middle- and lower-income panel, the results remain stable and do not substantially change compared to the specification without quadratic and cubic terms for affluence and thus appear to be very robust. Overall, for the high- (middle-) [lower-] income panel, the curve for $\mathrm{CO}_{2}$ emissions reaches the trough at an urbanization level of $60 \%(39 \%)$ [8\%], then increases up to the peak at $124 \%$ (55\%) [56\%] urbanization, and declines afterwards again. However, for the higher-income panel, the turning point for urbanization after which $\mathrm{CO}_{2}$ emissions decline again does not fall into the range of the urbanization ratio. 


\subsection{Discussion and Policy Implications}

Consistent across any income panel, the empirical analysis shows that the impact of population is a key determinant of $\mathrm{CO}_{2}$ emissions. However, GDP per capita does impact $\mathrm{CO}_{2}$ emissions greater in magnitude than population in any panel. The reaction in $\mathrm{CO}_{2}$ emissions due to a change in population is elastic for the middle-income panel only. This outcome does not change at all, when GDP per capita in quadratic and cubic terms is included. The results thus suggest, that it is rather growth in consumption than in people which causes $\mathrm{CO}_{2}$ emissions to increase. This paper thus contrasts the results from Fan et al. (2006), Poumanyvong and Kaneko (2010), Liddle (2013), Li and Lin (2015), Lin et al. (2017), Shuai et al. (2017), Martínez-Zarzoso and Maruotti (2011), Zhang and Chen (2017) who all find the impact of population not always to be smaller than the impact of GDP. Against the background that the poorest half of the global population is responsible for only around $10 \%$ of total emissions from consumption (Hardoon et al., 2016), reducing the contribution of wealthier groups in particular should be given priority to reduce $\mathrm{CO}_{2}$ emissions globally. Nevertheless, policy measures to combat climate change need to include population policies particularly as population growth is connected to $\mathrm{CO}_{2}$ emissions in at least two directions: it accelerates global warming via an increased number of consumers but rapidly growing population increases the number of people vulnerable to climate change, too. In this regard, policies supporting family planning programs and education on reproductive and sexual health, implementing the legal right to abortion, increasing the age of legal marriage, or further economic and social development reduces adolescent fertility or unintended pregnancies thus effectively increasing female empowerment. Slowing population growth in addition tends to enhance economic development and eventually reduces the number of people living in extreme poverty (Demeny, 1975; Pritchett, 1994; Casterline and Sinding, 2000; Stephenson et al., 2010). However, according to Pritchett (1994), it is unclear to what extent cultural and social norms determine fertility desires and Ehrlich and Holdren (1970) note that population policy measures clearly will be the slowest to have an effect.

The finding of an inverted N-shaped figure for the relationship between urbanization 
and $\mathrm{CO}_{2}$ emissions in any panel except of the high-income group shows that increasing urbanization levels tend to be beneficial to reducing emissions in the long-term perspective. The inverted N-shape figure turns into a N-shape figure for the all-income panel when GDP per capita in quadratic and cubic terms are included additionally, whereas we find an inverted $\mathrm{N}$-shaped figure for the relationship between urbanization and $\mathrm{CO}_{2}$ emissions in the high-income panel in the extended specification. Thus, the results suggest that in particular for middle- and lower-income countries where both urbanization levels is projected to increase the fastest, urbanization tends to offer the potential to reduce emissions in the long-term.

An inverted U-shaped pattern between urbanization and $\mathrm{CO}_{2}$ emissions is supported by Martínez-Zarzoso and Maruotti (2011) for upper-middle-income as well as lowermiddle-income panels and recently by Zhang and Chen (2017) for a panel of OECD countries. Both however, do not include a cubic term for urbanization which rules out the possibility of any other relation between urbanization and $\mathrm{CO}_{2}$ emissions than $\mathrm{U}$ - or inverted U-shaped. Cities, although responsible for more than $70 \%$ of global $\mathrm{CO}_{2}$ emissions in 2014 (UN-Habitat, 2016), generally seem to better provide conditions to solve social and environmental problems than rural areas. Following the compact city theory, urban agglomeration facilitates exploitation of economies of scale for public infrastructure such as sustainable public transportation modes, water supply, electricity production, schools, hospitals, and reduces car dependency, travel distance, the transmission and distribution losses of electricity at the same time. As a result, less energy is needed which eventually lowers $\mathrm{CO}_{2}$ emissions (Poumanyvong and Kaneko, 2010; Sadorsky, 2014). Summarizing available evidence for a sample of large cities in Asia, Europe, North America and Latin America, Dodman (2009) shows that per capita emissions from cities tend to be smaller compared to the average for the countries in which those cities are located. 


\section{Conclusions}

Using the STIRPAT regression framework in the context of the ecological modernization theory and understanding urbanization as an indicator of modernization, this paper analyzed if a threshold level for urbanization exists after which $\mathrm{CO}_{2}$ emissions decrease with further levels of urbanization. The relationship between affluence and $\mathrm{CO}_{2}$ emissions was analyzed in the context of the EKC hypothesis in addition, to check the robustness of the results. The balanced panel dataset of 76 countries over the period 1971 to 2014 was clustered into high-, middle-, and lower-income groups while also looking at the full sample. All groups were analyzed separately using non-stationary panel time series data methods. The results of the CD test (Pesaran, 2004) indicated the presence of cross-sectional dependence in the variables within all four panels except for the energy intensity indicator in the middle-income panel. The results of the second-generation panel unit root test (Pesaran, 2007) accounting for this cross-section dependence suggested that the series on $\mathrm{CO}_{2}$ emissions, population, GDP per capita, and energy intensity were integrated of order one in most panels. Thus, the presence of a unit root in the respective series the indicates that shocks will have permanent effects. A shock in the series on urbanization however, tends to result in only a temporary deviation from the variable's long-term growth path.

Unlike previous studies, this paper utilized dynamic panel estimation techniques which account for heterogeneity among countries and in which both the short- and long-term impacts are modeled. The outcome of the Hausman (1987) specification test suggested that the long-term relationship for $\mathrm{CO}_{2}$ emissions and its relevant demographic and economic factors tends to be similar across all groups. The magnitude of the effects however varies across the different income groups. The long-term estimation results from the PMG estimation provide evidence for cointegration and stability of the model: all error correction terms are highly statistically significant and negative in magnitude and not lower than -2 . The empirical results indicate that population is a significant impact factor within any panel only in the long-term. The insignificant short-run impact 
of population on $\mathrm{CO}_{2}$ emissions underlines that population effects only manifest over a very long period of time. In contrast to the literature, the long-term results show that GDP per capita greater impacts $\mathrm{CO}_{2}$ emissions than population consistently across panels. Moreover, output growth increases $\mathrm{CO}_{2}$ emissions the most in the lower-income panel in both the short- and the long-term. These results indicate, that energy efficiency reductions most harmfully effect $\mathrm{CO}_{2}$ emissions within the high-income panel in both the long- and short-run. The results for population and energy intensity do not change substantially, when analyzed in the context of the EKC hypothesis. We find the most robust evidence of an inverted N-shaped relationship between urbanization and $\mathrm{CO}_{2}$ emissions associated with the ecological modernization theory in particular for the lowerand middle-income panel. Thus, increasing levels of urbanization tend to reduce $\mathrm{CO}_{2}$ emissions in the long-term. The estimated turning point for the urbanization ratio after which $\mathrm{CO}_{2}$ emissions decline is almost identical for the lower- $(53.90 \%)$ and middle-income panel $(54.20 \%)$. The turning points remain statistically significant in a specification within an EKC regression framework and do not change substantially in magnitude.

Urbanization is key for a structural transformation for economies to modernize which facilitates economies of scale in infrastructure, capital and labour, as well as spill-over effects to eventually foster economic development. Similarly, economic development encourages rural to urban migration (Liddle and Messins, 2015). The existence of an inverted N-shaped relationship between urbanization and $\mathrm{CO}_{2}$ emissions however does not guarantee that accelerating urbanization automatically decreases emissions. Managing the transition from rural to urban centers remains a challenge to avoid negative aspects of urbanization such as traffic congestion, overcrowding, and air pollution, which would effectively outweigh the advantages of urbanization's potential to reduce $\mathrm{CO}_{2}$ emissions. The implementation of the infrastructure to encourage the development of urban centers to exploit economies of scale is important since it offers the potential to reduce $\mathrm{CO}_{2}$ emissions particularly in the lower- and middle-income countries. In addition, the demographic transition from rural to urban areas is accompanied by changes in terms of both economic and social structures such as the development of manufacturing and service oriented economies or 
environmental movements which may influence environmental policy decisions. As urban areas are considered to be highly vulnerable to anomalous climate events, sea-level rise, an increase in the frequency of heat waves, storms and floods, it is equally important to implement adaption strategies to increase cities resilience to climate change (Dodman, 2009). 


\section{References}

Banerjee, A., Marcellino, M. and Osbat, C., (2004). Some cautions on the use of panel methods for integrated series of macroeconomic data. The Econometrics Journal, 7(2): $322-340$.

Casterline, J.B. and Sinding, S.W., (2000). Unmet need for family planning in developing countries and implications for population policy. Population and development review 26(4): $691-723$.

Dinda, S., (2004). Environmental Kuznets curve hypothesis: a survey. Ecological economics, 49(4):431 - 455 .

Demeny, P., (1975). Population policy: The role of national governments. Population and Development Review 1(1): 147 - 161.

Dietz, T. and Rosa, E.A., (1994). Rethinking the environmental impacts of population, affluence and technology. Human ecology review 1(2): 277 - 300.

Dodman, D., 2009. Blaming cities for climate change? An analysis of urban greenhouse gas emissions inventories. Environment and urbanization 21(1): 185 - 201.

Ehrhardt-Martinez, K., 1998. Social determinants of deforestation in developing countries: a cross-national study. Social Forces 77(2): 567 - 586.

Ehrlich, P., and Holdren, J., (1970). The people problem. Saturday Review 4(42): 42 43.

Ehrlich, P., Holdren, J., (1972). A bulletin dialogue on the "Closing Circle": Critique: One dimensional ecology. Bulletin of the Atomic Scientists 28(5): 16 - 27.

Fan, Y., Liu, L.C., Wu, G., and Wei, Y.M., (2006). Analyzing impact factors of $\mathrm{CO}_{2}$ emissions using the STIRPAT model. Environmental Impact Assessment Review 26(4): $377-395$.

Grossman, G.M. and Krueger, A.B., (1991). Environmental impacts of a North American Free Trade Agreement. NBER Working Paper No. 3914.

Hsiao, C., (2014). Analysis of panel data, 3rd edition. Cambridge University Press, New York, United States of America.

Hausman, J.A., (1987). Specification tests in econometrics. Econometrica: Journal of the econometric society 46(6): $1251-1271$.

Kais, S., and Sami, H., (2016). An econometric study of the impact of economic growth and energy use on carbon emissions: panel data evidence from fifty eight countries. Renewable and Sustainable Energy Reviews 59: 1101 - 1110.

Kasarda, J.D. and Crenshaw, E.M., 1991. Third world urbanization: Dimensions, theories, and determinants. Annual Review of Sociology 17(1):467 - 501.

Kaya, Y., (1990). Impacts of carbon dioxide emission control on GNP growth: interpretation of proposed scenarios. In: Paper Presented to the IPCC Energy and Industry Subgroup, Response Strategies Working Group, Paris, France. 
Li, K. and Lin, B., (2015). Impacts of urbanization and industrialization on energy consumption/CO2 emissions: does the level of development matter? Renewable and Sustainable Energy Reviews 52: 1107 - 1122.

Liddle, B., (2013). Population, affluence, and environmental impact across development: evidence from panel cointegration modeling. Environmental modelling \& software 40: $255-266$.

Liddle, B., (2014). Impact of population, age structure, and urbanization on carbon emissions/energy consumption: evidence from macro-level, cross-country analyses. Population and Environment 35(3): 286 - 304.

Liddle, B., (2015). What are the carbon emissions elasticities for income and population? Bridging STIRPAT and EKC via robust heterogeneous panel estimates. Global Environmental Change 31: 62 - 73 .

Liddle, B. and Messinis, G., (2015). Which comes first-urbanization or economic growth? Evidence from heterogeneous panel causality tests. Applied Economics Letters 22(5): $349-355$.

Liddle, B., and Lung, S., (2010). Age-structure, urbanization, and climate change in developed countries: revisiting STIRPAT for disaggregated population and consumptionrelated environmental impacts. Population and Environment 31(5): 317 - 343.

Lin, S., Wang, S., Marinova, D., Zhao, D., and Hong, J., (2017). Impacts of urbanization and real economic development on $\mathrm{CO}_{2}$ emissions in non-high income countries: Empirical research based on the extended STIRPAT model. Journal of Cleaner Production Volume 166: 952 - 966.

Loayza, N.V. and Ranciere, R., (2006). Financial development, financial fragility, and growth. Journal of Money, Credit and Banking 38(4): 1051 - 1076.

Martínez-Zarzoso, I. and Maruotti, A., (2011). The impact of urbanization on CO2 emissions: evidence from developing countries. Ecological Economics 70(7): 1344 1353.

Mol, A.P. and Spaargaren, G., (2000). Ecological modernisation theory in debate: a review. Environmental politics, 9(1): 17 - 49.

Montgomery, D.C., Peck, E.A. and Vining, G.G., (2001). Introduction to linear regression analysis (Vol. 821). John Wiley \& Sons.

Pesaran, M.H., (1997). The role of economic theory in modelling the long run. The Economic Journal 107(440): 178 - 191.

Pesaran, M.H., (2004). General diagnostic tests for cross section dependence in panels. IZA Discussion Paper Series No. 1240.

Pesaran, M.H., (2007). A simple panel unit root test in the presence of cross-section dependence. Journal of Applied Econometrics 22(2):265 - 312.

Pesaran, M.H. and Smith, R., (1995). Estimating long-run relationships from dynamic heterogeneous panels. Journal of econometrics 68(1): 79 - 113. 
Pesaran, M.H., Shin, Y. and Smith, R.P., (1999). Pooled mean group estimation of dynamic heterogeneous panels. Journal of the American Statistical Association 94(446): $621-634$.

Pesaran, M.H., Shin, Y. and Smith, R.J., (2001). Bounds testing approaches to the analysis of level relationships. Journal of applied econometrics 16(3): $289-326$.

Pritchett, L.H., (1994). Desired fertility and the impact of population policies. Population and Development Review 20(1): 1 - 55 .

Poumanyvong, P., and Kaneko, S., (2010). Does urbanization lead to less energy use and lower $\mathrm{CO}_{2}$ emissions? A cross-country analysis. Ecological Economics 70(2): 434 444 .

Sadorsky, P., (2014). The effect of urbanization on $\mathrm{CO}_{2}$ emissions in emerging economies. Energy Economics 41: 147 - 153.

Shuai, C., Shen, L., Jiao, L., Wu, Y., and Tan, Y., (2017). Identifying key impact factors on carbon emission: Evidences from panel and time-series data of 125 countries from 1990 to 2011. Applied Energy 187: 310 - 325.

Smyth, R., 2013. Are fluctuations in energy variables permanent or transitory? A survey of the literature on the integration properties of energy consumption and production. Applied Energy 104: 371 - 378.

Stephenson, J., Newman, K., and Mayhew, S., (2010). Population dynamics and climate change: what are the links?. Journal of Public Health, 32(2): 150 - 156.

United Nations (UN), (2014). World Urbanization Prospects: The 2014 Revision. Department of Economic and Social Affairs, Population Division, New York, United States.

UN-Habitat, (2016). Urbanization and Development: Emerging Futures. World Cities Report 2016. United Nations Human Settlements Programme (UN-Habitat), Nairobi, Kenya.

United Nations (UN), (2017). World Population Prospects: The 2017 Revision. Key Findings and Advance Tables. Department of Economic and Social Affairs, Population Division, New York, United States.

York, R. and Rosa, E.A., (2003). Key challenges to ecological modernization theory: Institutional efficacy, case study evidence, units of analysis, and the pace of ecoefficiency. Organization \& Environment, 16(3): 273 - 288.

York, R., Rosa, E.A., and Dietz, T., (2003a). STIRPAT, IPAT and ImPACT: analytic tools for unpacking the driving forces of environmental impacts. Ecological economics 46(3): $351-365$.

York, R., Rosa, E.A. and Dietz, T., (2003b). Footprints on the earth: The environmental consequences of modernity. American sociological review 68(2): 279 - 300.

York, R., Rosa, E.A. and Dietz, T., (2003c). A rift in modernity? Assessing the anthropogenic sources of global climate change with the STIRPAT model. International Journal of Sociology and Social Policy, 23(10): 31 - 51. 
York, R., Rosa, E.A. and Dietz, T., (2010). Ecological modernization theory: theoretical and empirical challenges. The international handbook of environmental sociology. Eds. Edward Elgar Publishing. 77 - 90.

Zhang, N., Yu, K. and Chen, Z., (2017). How does urbanization affect carbon dioxide emissions? A cross-country panel data analysis. Energy Policy 107: 678 - 687. 


\section{A Appendix}

Table 2: Multicollinearity test

\begin{tabular}{|c|c|c|c|c|c|c|c|c|}
\hline \multirow[b]{2}{*}{ Explanatory variables } & \multicolumn{2}{|c|}{ All-income } & \multicolumn{2}{|c|}{ High-income } & \multicolumn{2}{|c|}{ Middle-income } & \multicolumn{2}{|c|}{ Lower-income } \\
\hline & VIF & Mean VIF & VIF & Mean VIF & VIF & Mean VIF & VIF & Mean VIF \\
\hline$P$ & 1.09 & & 1.03 & & 1.13 & & 1.15 & \\
\hline$G D P$ & 3.86 & 250 & 1.30 & 115 & 2.58 & 180 & 4.89 & 308 \\
\hline$E I$ & 2.70 & 2.59 & 1.18 & 1.15 & 1.81 & 1.89 & 4.63 & 3.08 \\
\hline$U$ & 2.73 & & 1.09 & & 2.03 & & 1.65 & \\
\hline
\end{tabular}

Notes: All variables in natural logarithms.

Table 3: Results of Pesaran (2004) CD tests

\begin{tabular}{|c|c|c|c|c|c|c|c|c|}
\hline & & \multicolumn{7}{|c|}{ Variables in levels } \\
\hline & & $\mathrm{CO}_{2}$ & $P$ & $G D P$ & $E I$ & $U$ & $U^{2}$ & $U^{3}$ \\
\hline 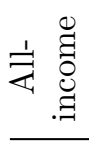 & $\begin{array}{l}\text { abs (corr) } \\
\text { CD statistic }\end{array}$ & $\begin{array}{c}0.73 \\
184.33^{a} \\
(0.00)\end{array}$ & $\begin{array}{c}0.97 \\
344.23^{a} \\
(0.00)\end{array}$ & $\begin{array}{c}0.71 \\
190.37^{a} \\
(0.00)\end{array}$ & $\begin{array}{c}0.54 \\
44.76^{a} \\
(0.00)\end{array}$ & $\begin{array}{c}0.88 \\
289.26^{a} \\
(0.00)\end{array}$ & $\begin{array}{c}0.88 \\
288.82^{a} \\
(0.00)\end{array}$ & $\begin{array}{c}0.88 \\
288.29^{a} \\
(0.00)\end{array}$ \\
\hline 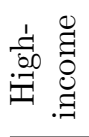 & $\begin{array}{l}\text { abs }(\text { corr }) \\
\text { CD statistic }\end{array}$ & $\begin{array}{c}0.68 \\
47.36^{a} \\
(0.00)\end{array}$ & $\begin{array}{c}0.95 \\
135.38^{a} \\
(0.00)\end{array}$ & $\begin{array}{c}0.89 \\
115.86^{a} \\
(0.00)\end{array}$ & $\begin{array}{c}0.68 \\
43.47^{a} \\
(0.00)\end{array}$ & $\begin{array}{c}0.85 \\
104.84^{a} \\
(0.00)\end{array}$ & $\begin{array}{c}0.85 \\
104.85^{a} \\
(0.00)\end{array}$ & $\begin{array}{c}0.85 \\
104.84^{a} \\
(0.00)\end{array}$ \\
\hline 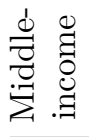 & $\begin{array}{l}\text { abs }(\text { corr }) \\
\text { CD statistic }\end{array}$ & $\begin{array}{c}0.74 \\
64.77^{a} \\
(0.00)\end{array}$ & $\begin{array}{c}0.99 \\
90.81^{a} \\
(0.00)\end{array}$ & $\begin{array}{c}0.66 \\
49.13^{a} \\
(0.00)\end{array}$ & $\begin{array}{c}0.42 \\
-0.79 \\
(0.43)\end{array}$ & $\begin{array}{c}0.95 \\
87.00^{a} \\
(0.00)\end{array}$ & $\begin{array}{c}0.95 \\
86.84^{a} \\
(0.00)\end{array}$ & $\begin{array}{c}0.95 \\
86.65^{a} \\
(0.00)\end{array}$ \\
\hline 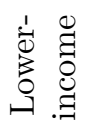 & $\begin{array}{l}\text { abs }(\text { corr }) \\
\text { CD statistic }\end{array}$ & $\begin{array}{c}0.78 \\
80.75^{a} \\
(0.00)\end{array}$ & $\begin{array}{c}0.99 \\
114.18^{a} \\
(0.00)\end{array}$ & $\begin{array}{c}0.60 \\
37.97^{a} \\
(0.00)\end{array}$ & $\begin{array}{c}0.49 \\
7.54^{a} \\
(0.00)\end{array}$ & $\begin{array}{c}0.85 \\
93.26^{a} \\
(0.00)\end{array}$ & $\begin{array}{c}0.85 \\
92.85^{a} \\
(0.00)\end{array}$ & $\begin{array}{c}0.85 \\
92.42^{a} \\
(0.00)\end{array}$ \\
\hline
\end{tabular}

Notes: P-values are in parentheses; superscripts $a, b$, and $c$ represent significance at $1 \%$, $5 \%$, and $10 \%$, respectively; all variables in natural logarithms. 
Table 4: Results of Pesaran (2007) panel unit root tests

\begin{tabular}{|c|c|c|c|c|c|c|c|c|}
\hline & \multicolumn{2}{|c|}{ All-income } & \multicolumn{2}{|c|}{ High-income } & \multicolumn{2}{|c|}{ Middle-income } & \multicolumn{2}{|c|}{ Lower-income } \\
\hline & No Trend & Trend & No Trend & Trend & No Trend & Trend & No Trend & Trend \\
\hline $\mathrm{CO}_{2}$ & -2.030 & -2.016 & -1.924 & -2.168 & -1.963 & -2.122 & $-2.119^{b}$ & -2.503 \\
\hline$P$ & -1.994 & $-3.094^{a}$ & -1.888 & -1.931 & $-2.328^{a}$ & $-3.913^{a}$ & $-2.259^{a}$ & $-3.852^{a}$ \\
\hline$G D P$ & -1.593 & -2.303 & -1.750 & -1.756 & -1.795 & -2.457 & -1.642 & $-2.688^{b}$ \\
\hline$E I$ & -1.883 & $-2.600^{c}$ & -1.914 & $-2.553^{c}$ & -2.018 & -2.470 & -1.625 & $-2.570^{c}$ \\
\hline$U$ & $-2.713^{a}$ & $-3.016^{a}$ & $-2.442^{a}$ & $-2.802^{a}$ & $-2.384^{a}$ & -2.236 & $-2.885^{a}$ & $-3.077^{a}$ \\
\hline$U^{2}$ & $-2.657^{a}$ & $-3.006^{a}$ & $-2.420^{a}$ & $-2.778^{a}$ & $-2.351^{a}$ & -2.323 & $-2.837^{a}$ & $-2.824^{a}$ \\
\hline$U^{3}$ & $-2.532^{a}$ & $-2.951^{a}$ & $-2.390^{a}$ & $-2.775^{a}$ & $-2.352^{a}$ & -2.209 & $-2.790^{a}$ & $-2.698^{b}$ \\
\hline$\Delta C O_{2}$ & $-5.649^{a}$ & $-6.015^{a}$ & $-5.738^{a}$ & $-5.970^{a}$ & $-5.746^{a}$ & $-5.890^{a}$ & $-5.816^{a}$ & $-6.033^{a}$ \\
\hline$\Delta P$ & $-2.437^{a}$ & $-2.755^{a}$ & $-2.198^{b}$ & $-2.884^{a}$ & $-2.572^{a}$ & $-2.921^{a}$ & $-2.712^{a}$ & $-3.414^{a}$ \\
\hline$\triangle G D P$ & $-4.504^{a}$ & $-4.816^{a}$ & $-4.366^{a}$ & $-4.673^{a}$ & $-4.729^{a}$ & $-4.884^{a}$ & $-4.843^{a}$ & $-5.218^{a}$ \\
\hline$\Delta E I$ & $-5.791^{a}$ & $-5.986^{a}$ & $-5.887^{a}$ & $-6.213^{a}$ & $-5.701^{a}$ & $-5.973^{a}$ & $-5.777^{a}$ & $-5.971^{a}$ \\
\hline$\Delta U$ & -1.989 & -2.451 & -1.644 & -2.150 & -1.780 & -2.256 & -1.996 & -2.036 \\
\hline$\Delta U^{2}$ & -1.937 & -2.337 & -1.638 & -2.124 & -1.673 & -2.277 & -2.001 & -1.920 \\
\hline$\Delta U^{3}$ & -1.928 & -2.291 & -1.632 & -2.113 & -1.593 & -2.312 & -1.948 & -1.870 \\
\hline
\end{tabular}

Notes: Superscripts $a, b$, and $c$ represent significance at $1 \%, 5 \%$, and $10 \%$, respectively; critical values are from Pesaran (2007).

Table 5: List of 76 countries

High-income panel (31):

Argentina, Australia, Austria, Belgium, Canada, Chile, Denmark, Finland, France, Greece, Ireland, Israel, Italy, Hong Kong, Japan, Korea, Rep., Luxembourg, Malta, Netherlands,

New Zealand, Norway, Oman, Panama, Portugal, Saudi Arabia, Spain, Sweden,

Trinidad and Tobago, United Kingdom, United States, Uruguay

Middle-income (20):

Algeria, Brazil, China, Colombia, Costa Rica, Cuba, Dominican Republic, Ecuador, Gabon,

Guatemala, Iran, Islamic Rep., Iraq, Jamaica, Malaysia, Mexico, Paraguay, Peru, South Africa, Thailand, Turkey

Lower-income (25):

Benin, Bolivia, Cameroon, Congo, Dem. Rep., Congo, Rep., Cote d'Ivoire, Egypt, Arab Rep., El Salvador, Ghana, Honduras, India, Indonesia, Kenya, Morocco, Myanmar, Nepal, Nicaragua, Nigeria, Pakistan, Philippines, Senegal, Sri Lanka, Sudan, Togo, Tunisia

Notes: Originally, the World Bank clusters economies into low, lower-middle, upper-middle, and high-income groups. 
Table 6: ARDL $(1,1,1,1,1,1,1)$ estimation and Hausman (1987) test results

\begin{tabular}{|c|c|c|c|c|c|c|c|c|}
\hline & \multicolumn{2}{|c|}{ All-income } & \multicolumn{2}{|c|}{ High-income } & \multicolumn{2}{|c|}{ Middle-income } & \multicolumn{2}{|c|}{ Lower-income } \\
\hline & MG & PMG & MG & PMG & MG & PMG & MG & PMG \\
\hline & \multicolumn{8}{|c|}{ long-term coefficients } \\
\hline$P$ & $\begin{array}{l}2.168^{b} \\
(2.09)\end{array}$ & $\begin{array}{c}0.855^{a} \\
(18.37)\end{array}$ & $\begin{array}{l}-0.535 \\
(-0.70)\end{array}$ & $\begin{array}{l}0.411^{a} \\
(5.13)\end{array}$ & $\begin{array}{l}1.204 \\
(1.38)\end{array}$ & $\begin{array}{l}1.160^{a} \\
(13.35)\end{array}$ & $\begin{array}{l}6.292^{b} \\
(2.27)\end{array}$ & $\begin{array}{c}0.594^{a} \\
(5.77)\end{array}$ \\
\hline$G D P$ & $\begin{array}{l}1.559^{a} \\
(8.87)\end{array}$ & $\begin{array}{l}1.031^{a} \\
(56.35)\end{array}$ & $\begin{array}{l}1.157^{a} \\
(10.90)\end{array}$ & $\begin{array}{l}1.026^{a} \\
(38.38)\end{array}$ & $\begin{array}{l}1.208^{a} \\
(7.48)\end{array}$ & $\begin{array}{l}1.174^{a} \\
(27.60)\end{array}$ & $\begin{array}{r}2.337^{a} \\
(4.97)\end{array}$ & $\begin{array}{l}1.272^{a} \\
(20.98)\end{array}$ \\
\hline$E I$ & $\begin{array}{l}1.120^{a} \\
(7.70)\end{array}$ & $\begin{array}{l}0.972^{a} \\
(44.32)\end{array}$ & $\begin{array}{l}1.204^{a} \\
(10.86)\end{array}$ & $\begin{array}{l}1.065^{a} \\
(29.97)\end{array}$ & $\begin{array}{c}0.518^{a} \\
(3.38)\end{array}$ & $\begin{array}{l}0.838^{a} \\
(17.85)\end{array}$ & $\begin{array}{l}1.498^{a} \\
(3.88)\end{array}$ & $\begin{array}{c}0.833^{a} \\
(14.15)\end{array}$ \\
\hline$U$ & $\begin{array}{l}108.5 \\
(0.31)\end{array}$ & $\begin{array}{l}-13.30^{b} \\
(-2.28)\end{array}$ & $\begin{array}{l}309.7 \\
(1.17)\end{array}$ & $\begin{array}{l}90.34 \\
(1.19)\end{array}$ & $\begin{array}{l}230.1 \\
(0.31)\end{array}$ & $\begin{array}{l}-143.0^{a} \\
(-3.81)\end{array}$ & $\begin{array}{l}-238.4 \\
(-0.28)\end{array}$ & $\begin{array}{l}-25.71^{a} \\
(-2.84)\end{array}$ \\
\hline$U^{2}$ & $\begin{array}{l}-50.67 \\
(-0.55)\end{array}$ & $\begin{array}{l}4.212^{a} \\
(2.72)\end{array}$ & $\begin{array}{l}-91.44 \\
(-1.37)\end{array}$ & $\begin{array}{l}-25.72 \\
(-1.43)\end{array}$ & $\begin{array}{l}-77.06 \\
(-0.40)\end{array}$ & $\begin{array}{l}37.38^{a} \\
(4.01)\end{array}$ & $\begin{array}{l}21.01 \\
(0.09)\end{array}$ & $\begin{array}{l}9.394^{a} \\
(3.37)\end{array}$ \\
\hline \multirow[t]{2}{*}{$U^{3}$} & $\begin{array}{l}6.358 \\
(0.77) \\
\end{array}$ & $\begin{array}{r}-0.418^{a} \\
(-3.05) \\
\end{array}$ & $\begin{array}{l}8.508 \\
(1.31) \\
\end{array}$ & $\begin{array}{l}2.357^{c} \\
(1.66)\end{array}$ & $\begin{array}{l}7.655 \\
(0.48) \\
\end{array}$ & $\begin{array}{r}-3.252^{a} \\
(-4.21) \\
\end{array}$ & $\begin{array}{l}2.653 \\
(0.13) \\
\end{array}$ & $\begin{array}{r}-1.032^{a} \\
(-3.71) \\
\end{array}$ \\
\hline & \multicolumn{8}{|c|}{ ECM equation } \\
\hline ec & $\begin{array}{l}-0.768^{a} \\
(-24.00)\end{array}$ & $\begin{array}{l}-0.417^{a} \\
(-11.98)\end{array}$ & $\begin{array}{l}-0.645^{a} \\
(-13.12)\end{array}$ & $\begin{array}{l}-0.294^{a} \\
(-7.11)\end{array}$ & $\begin{array}{l}-0.830^{a} \\
(-14.21)\end{array}$ & $\begin{array}{c}-0.533^{a} \\
(-8.50)\end{array}$ & $\begin{array}{l}-0.869^{a} \\
(-17.49)\end{array}$ & $\begin{array}{c}-0.523^{a} \\
(-9.48)\end{array}$ \\
\hline$\Delta P$ & $\begin{array}{l}4.627 \\
(1.00)\end{array}$ & $\begin{array}{l}1.425 \\
(0.68)\end{array}$ & $\begin{array}{l}2.602 \\
(1.42)\end{array}$ & $\begin{array}{l}-1.967 \\
(-0.87)\end{array}$ & $\begin{array}{l}0.588 \\
(0.10)\end{array}$ & $\begin{array}{l}-4.467 \\
(-1.38)\end{array}$ & $\begin{array}{l}10.37 \\
(0.78)\end{array}$ & $\begin{array}{l}9.285^{c} \\
(1.74)\end{array}$ \\
\hline$\triangle G D P$ & $\begin{array}{l}0.166 \\
(1.52)\end{array}$ & $\begin{array}{c}0.843^{a} \\
(7.80)\end{array}$ & $\begin{array}{l}0.348^{a} \\
(3.82)\end{array}$ & $\begin{array}{c}0.811^{a} \\
(10.26)\end{array}$ & $\begin{array}{l}0.114 \\
(0.73)\end{array}$ & $\begin{array}{l}0.466^{a} \\
(2.87)\end{array}$ & $\begin{array}{c}-0.0171 \\
(-0.06)\end{array}$ & $\begin{array}{l}1.015^{a} \\
(3.52)\end{array}$ \\
\hline$\Delta E I$ & $\begin{array}{l}0.139 \\
(1.55)\end{array}$ & $\begin{array}{c}0.525^{a} \\
(6.07)\end{array}$ & $\begin{array}{c}0.326^{a} \\
(4.38)\end{array}$ & $\begin{array}{c}0.720^{a} \\
(9.17)\end{array}$ & $\begin{array}{l}0.123 \\
(1.25)\end{array}$ & $\begin{array}{l}0.233^{b} \\
(2.04)\end{array}$ & $\begin{array}{c}-0.0820 \\
(-0.34)\end{array}$ & $\begin{array}{l}0.524^{b} \\
(2.36)\end{array}$ \\
\hline$\Delta U$ & $\begin{array}{c}-5480.9 \\
(-1.11)\end{array}$ & $\begin{array}{l}-710.3 \\
(-0.54)\end{array}$ & $\begin{array}{l}69.76 \\
(0.02)\end{array}$ & $\begin{array}{l}-6.664 \\
(-0.00)\end{array}$ & $\begin{array}{l}-771.4 \\
(-0.05)\end{array}$ & $\begin{array}{c}-2635.2 \\
(-1.20)\end{array}$ & $\begin{array}{c}-16131.4^{b} \\
(-1.96)\end{array}$ & $\begin{array}{c}-2709.4 \\
(-1.26)\end{array}$ \\
\hline$\Delta U^{2}$ & $\begin{array}{l}1458.4 \\
(1.11)\end{array}$ & $\begin{array}{l}253.6 \\
(0.72)\end{array}$ & $\begin{array}{l}-121.3 \\
(-0.17)\end{array}$ & $\begin{array}{l}26.16 \\
(0.05)\end{array}$ & $\begin{array}{l}-256.7 \\
(-0.07)\end{array}$ & $\begin{array}{l}672.3 \\
(1.22)\end{array}$ & $\begin{array}{c}4789.3^{b} \\
(2.01)\end{array}$ & $\begin{array}{l}872.3 \\
(1.27)\end{array}$ \\
\hline$\Delta U^{3}$ & $\begin{array}{l}-135.9 \\
(-1.14)\end{array}$ & $\begin{array}{l}-29.12 \\
(-0.85)\end{array}$ & $\begin{array}{l}16.58 \\
(0.30)\end{array}$ & $\begin{array}{l}-3.572 \\
(-0.08)\end{array}$ & $\begin{array}{l}59.86 \\
(0.18)\end{array}$ & $\begin{array}{l}-57.04 \\
(-1.24)\end{array}$ & $\begin{array}{l}-481.6^{b} \\
(-2.05)\end{array}$ & $\begin{array}{l}-95.10 \\
(-1.27)\end{array}$ \\
\hline _cons & $\begin{array}{l}-162.8 \\
(-0.35)\end{array}$ & $\begin{array}{r}0.642^{a} \\
(6.88)\end{array}$ & $\begin{array}{l}-280.8 \\
(-0.86)\end{array}$ & $\begin{array}{r}-30.65^{a} \\
(-7.07)\end{array}$ & $\begin{array}{l}-292.4 \\
(-0.25)\end{array}$ & $\begin{array}{r}87.94^{a} \\
(8.48)\end{array}$ & $\begin{array}{l}87.30 \\
(0.09)\end{array}$ & $\begin{array}{l}5.178^{a} \\
(8.97)\end{array}$ \\
\hline \multicolumn{9}{|c|}{ Hausman test } \\
\hline & $\operatorname{chi} 2(6)$ & prob chi2 & $\operatorname{chi} 2(6)$ & prob chi2 & $\operatorname{chi} 2(6)$ & prob chi2 & $\operatorname{chi} 2(6)$ & prob chi2 \\
\hline & 6.82 & 0.3379 & 5.02 & 0.5415 & 8.53 & 0.2016 & 6.15 & 0.4065 \\
\hline
\end{tabular}

Notes: t-statistics in parentheses; superscripts $a, b$, and $c$ represent significance at $1 \%, 5 \%$, and $10 \%$, respectively; all variables in natural logarithms. 
Table 7: ARDL(1,1,1,1,1,1,1,1,1) estimation and Hausman (1987) test results

\begin{tabular}{|c|c|c|c|c|c|c|c|c|}
\hline & \multicolumn{2}{|c|}{ All-income } & \multicolumn{2}{|c|}{ High-income } & \multicolumn{2}{|c|}{ Middle-income } & \multicolumn{2}{|c|}{ Lower-income } \\
\hline & MG & PMG & MG & PMG & MG & PMG & MG & PMG \\
\hline & \multicolumn{8}{|c|}{ long-term coefficients } \\
\hline \multirow[t]{2}{*}{$P$} & 0.922 & $0.664^{a}$ & -0.0756 & $0.718^{a}$ & 0.996 & $1.150^{a}$ & 2.101 & $0.585^{a}$ \\
\hline & $(1.01)$ & $(12.82)$ & $(-0.12)$ & $(6.20)$ & (1.03) & $(12.93)$ & $(0.81)$ & $(5.74)$ \\
\hline \multirow[t]{2}{*}{$G D P$} & -208.4 & $1.510^{c}$ & -49.76 & $-8.080^{c}$ & -57.43 & $36.04^{a}$ & -525.9 & 3.035 \\
\hline & $(-0.66)$ & $(1.77)$ & $(-0.30)$ & $(-1.82)$ & $(-0.43)$ & $(4.34)$ & $(-0.55)$ & $(0.89)$ \\
\hline \multirow[t]{2}{*}{$G D P^{2}$} & 29.75 & 0.0371 & 4.097 & $1.063^{b}$ & 6.146 & $-3.983^{a}$ & 80.45 & -0.125 \\
\hline & $(0.69)$ & $(0.38)$ & $(0.26)$ & $(2.30)$ & $(0.39)$ & $(-4.07)$ & $(0.62)$ & $(-0.26)$ \\
\hline \multirow{2}{*}{$G D P^{3}$} & -1.422 & -0.00480 & -0.105 & $-0.0413^{a}$ & -0.208 & $0.151^{a}$ & -4.028 & 0.000725 \\
\hline & $(-0.71)$ & $(-1.30)$ & $(-0.20)$ & $(-2.58)$ & $(-0.34)$ & $(3.95)$ & $(-0.67)$ & $(0.03)$ \\
\hline \multirow[t]{2}{*}{$E I$} & $1.086^{a}$ & $0.943^{a}$ & $1.111^{a}$ & $0.968^{a}$ & $0.564^{a}$ & $0.872^{a}$ & $1.472^{a}$ & $0.901^{a}$ \\
\hline & $(8.21)$ & $(39.49)$ & $(11.59)$ & $(31.69)$ & $(3.76)$ & $(18.69)$ & $(4.21)$ & $(13.99)$ \\
\hline \multirow[t]{2}{*}{$U$} & 18.76 & $13.88^{b}$ & 228.4 & $-181.7^{c}$ & $-545.6^{c}$ & $-117.6^{a}$ & 210.3 & $-15.73^{c}$ \\
\hline & $(0.05)$ & $(2.45)$ & $(0.87)$ & $(-1.96)$ & $(-1.75)$ & $(-6.43)$ & $(0.21)$ & $(-1.72)$ \\
\hline \multirow[t]{2}{*}{$U^{2}$} & -6.809 & $-3.573^{b}$ & -13.51 & $41.07^{c}$ & 120.6 & $30.78^{a}$ & -100.4 & $5.719^{b}$ \\
\hline & $(-0.07)$ & $(-2.52)$ & $(-0.17)$ & $(1.88)$ & $(1.47)$ & $(6.44)$ & $(-0.38)$ & $(2.03)$ \\
\hline \multirow[t]{3}{*}{$U^{3}$} & 1.338 & $0.318^{a}$ & -1.694 & $-3.073^{c}$ & -9.038 & $-2.679^{a}$ & 13.40 & $-0.624^{b}$ \\
\hline & $(0.15)$ & $(2.69)$ & $(-0.19)$ & $(-1.80)$ & $(-1.22)$ & $(-6.44)$ & $(0.57)$ & $(-2.19)$ \\
\hline & \multicolumn{8}{|c|}{ ECM equation } \\
\hline \multirow[t]{2}{*}{ ec } & $-0.878^{a}$ & $-0.434^{a}$ & $-0.748^{a}$ & $-0.326^{a}$ & $-0.973^{a}$ & $-0.570^{a}$ & $-0.963^{a}$ & $-0.543^{a}$ \\
\hline & $(-27.73)$ & $(-12.15)$ & $(-16.25)$ & $(-6.29)$ & $(-16.91)$ & $(-8.18)$ & $(-18.68)$ & $(-9.45)$ \\
\hline \multirow[t]{2}{*}{$\Delta P$} & -3.349 & 2.595 & 3.513 & -0.672 & -4.177 & -3.300 & -11.20 & 11.58 \\
\hline & $(-0.57)$ & $(1.01)$ & $(1.52)$ & $(-0.40)$ & $(-0.42)$ & $(-0.74)$ & $(-0.71)$ & $(1.60)$ \\
\hline \multirow[t]{2}{*}{$\triangle G D P$} & -76.47 & -302.9 & -200.4 & -9.286 & -122.6 & -89.17 & 114.1 & -770.0 \\
\hline & $(-0.25)$ & $(-1.48)$ & $(-1.59)$ & $(-0.09)$ & $(-0.43)$ & $(-0.60)$ & $(0.13)$ & $(-1.27)$ \\
\hline \multirow[t]{2}{*}{$\Delta G D P^{2}$} & 9.779 & 45.04 & 19.96 & 2.001 & 16.71 & 12.35 & -8.389 & 116.9 \\
\hline & $(0.22)$ & (1.54) & (1.64) & $(0.19)$ & $(0.48)$ & $(0.69)$ & $(-0.06)$ & $(1.33)$ \\
\hline \multirow[t]{2}{*}{$\Delta G D P^{3}$} & -0.469 & -2.228 & $-0.664^{c}$ & -0.102 & -0.751 & -0.557 & -0.00270 & -5.901 \\
\hline & $(-0.22)$ & $(-1.57)$ & $(-1.70)$ & $(-0.30)$ & $(-0.53)$ & $(-0.76)$ & $(-0.00)$ & $(-1.37)$ \\
\hline \multirow[t]{2}{*}{$\Delta E I$} & 0.0762 & $0.541^{a}$ & $0.221^{a}$ & $0.709^{a}$ & 0.000446 & $0.201^{c}$ & -0.0426 & $0.561^{b}$ \\
\hline & $(0.84)$ & $(6.03)$ & $(3.34)$ & $(8.62)$ & $(0.01)$ & $(1.73)$ & $(-0.17)$ & $(2.42)$ \\
\hline \multirow[t]{2}{*}{$\Delta U$} & -4283.0 & -1816.4 & 666.8 & -270.1 & -5264.7 & -2780.9 & -9635.3 & -3165.0 \\
\hline & $(-0.86)$ & $(-1.39)$ & $(0.19)$ & $(-0.11)$ & $(-0.38)$ & $(-1.31)$ & $(-1.02)$ & $(-1.47)$ \\
\hline \multirow[t]{2}{*}{$\Delta U^{2}$} & 1055.7 & 521.5 & -228.5 & 84.00 & 845.4 & 711.8 & 2816.2 & 978.7 \\
\hline & $(0.82)$ & $(1.55)$ & $(-0.28)$ & $(0.15)$ & $(0.24)$ & $(1.33)$ & $(1.09)$ & $(1.46)$ \\
\hline \multirow[t]{2}{*}{$\Delta U^{3}$} & -91.36 & -50.53 & 22.45 & -8.079 & -30.17 & -60.56 & -281.4 & -102.8 \\
\hline & $(-0.80)$ & $(-1.63)$ & $(0.36)$ & $(-0.19)$ & $(-0.10)$ & $(-1.33)$ & $(-1.17)$ & $(-1.43)$ \\
\hline _cons & 450.4 & $-13.22^{a}$ & -496.4 & $92.43^{a}$ & 934.4 & $17.77^{a}$ & 1237.4 & $-1.998^{a}$ \\
\hline & $(0.55)$ & $(-12.18)$ & $(-0.83)$ & $(6.30)$ & $(1.65)$ & $(8.09)$ & $(0.52)$ & $(-7.26)$ \\
\hline & & & & Hausn & an test & & & \\
\hline & $\operatorname{chi} 2(7)$ & prob chi2 & $\operatorname{chi2}(7)$ & prob chi2 & $\operatorname{chi} 2(7)$ & prob chi2 & $\operatorname{chi} 2(7)$ & prob chi2 \\
\hline & 1.21 & 0.9906 & 4.53 & 0.7168 & 5.76 & 0.5681 & 3.69 & 0.8147 \\
\hline
\end{tabular}

Notes: t-statistics in parentheses; superscripts $a, b$, and $c$ represent significance at $1 \%, 5 \%$, and $10 \%$, respectively; all variables in natural logarithms. 